\title{
A Forest Fire Theory of Recessions and Unemployment
}

\author{
Matthew O. Jackson and Pietro Tebaldi* \\ Draft: January 2014
}

\begin{abstract}
We develop a model of matching from firms' perspectives and draw resulting conclusions for the macro-dynamics of an economy. The key insight is that firms may wish to hire workers that are bad matches (having low productivity) in high-demand states, even if the worker must be hired to a long-run contract. This results an increasing fraction of bad worker-firm matches as an economy booms, making it increasingly likely that a recession will occur the longer it has been since the last recession, and increasing the depth of the recession when it occurs. While employment is lowest immediately following a recession, an economy has its highest fraction of good to bad matches as it emerges from a recession. These dynamics result in fully-rational, endogenous business cycles featuring non-stationary distributions of unemployment for a given stationary exogenous shock: in particular, the longer it has been since the last recession the more fragile the economy becomes and the more dramatic its response to exogenous shocks. Examining US economic areas data from 1969-2011, we find that the longer the time elapsed since the last recession, the larger the drop in employment during the recession.

Keywords: recessions, employment, unemployment, matching, search, business cycles, macro-dynamics
\end{abstract}

JEL Classification Codes: E24, E32, D92, D21, D22

*Department of Economics, Stanford University, Stanford, California 94305-6072 USA. Jackson is also an external faculty member at the Santa Fe Institute and a fellow of CIFAR. Emails: jacksonm@stanford.edu and ptebaldi@stanford.edu. Financial support from the NSF under grant SES-1155302 as well as from Microsoft Research New England is gratefully acknowledged. We thank Bob Hall, Pat Kehoe, Christian Hellwig, Moritz Lenel, Pablo Kurlat, and participants at the Midwest Macroeconomics Conference at the University of Minnesota for helpful comments. 
Capitalism, then, is by nature a form or method of economic change and not only never is but never can be stationary... This process of Creative Destruction is the essential fact about capitalism. It is what capitalism consists in and what every capitalist concern has got to live in.

Joseph Schumpeter, Capitalism, Socialism and Democracy, 1942

\section{Introduction}

Facets of the destructive nature of capitalism play prominent roles in a spectrum of economic theories, from those underlying the Marxist class conflict that accompanies accumulation of capital to the Schumpeterian (1939) creative destruction that accompanies innovation and growth. 1

Here we document and provide a theory for aspects of cycles of growth and destruction that naturally emerge in an economy but that have not been documented before. In particular, the longer an economy has gone without a recession, the deeper the subsequent recession. This has an analogy to forest fires, in that the longer it has been since the last fire the more fuel builds up and the larger the subsequent fire. Ours is not simply a model of creative destruction, but one with a new form of nonstationarity that matches novel empirical observations that we also present.

Let us first briefly point out that this aspect of deeper drops following longer expansions appears strongly in the data. For this illustration, we use a 42 year panel of regional level data, and define the onset of a 'crisis' as a year of negative growth of proprietors' income preceded by one or more periods of positive growth, which we call 'an expansion'. In Figure 1 we report the histogram of the deviation in the growth of (wage and salary) jobs from its expansion average for different durations of expansion. The figure suggests that the extent to which employment drops in a recession is larger the longer the preceding expansionary period. In Section 4 we provide the detailed analysis of these data.

The model that we build that matches these features is one in which there are some search frictions in hiring in the economy. In times where demand is high, firms facing even small frictions in searching for workers may be willing to (fully rationally) hire workers that are less than optimal matches. In times of high demand it may be better to hire some labor that is a poor match for the firm's productive process than to delay in waiting for a new match, even if that requires hiring on a long-term contract. The current gain in profits can outweigh the future discounted expected cost of the hiring low-quality matches.

The key ingredients are that there may be some delay in finding another worker due to

\footnotetext{
${ }^{1}$ For more background and modern analyses of creative destruction, and a few papers from the literature offering detailed analyses of productivity changes and business cycles, see Gali and Hammour (1992), Davis and Haltiwanger (1992), Caballero and Hammour (1994, 1996), Acemoglu and Autor (2010), and Jaimovich and Siu $(2012)$.
} 


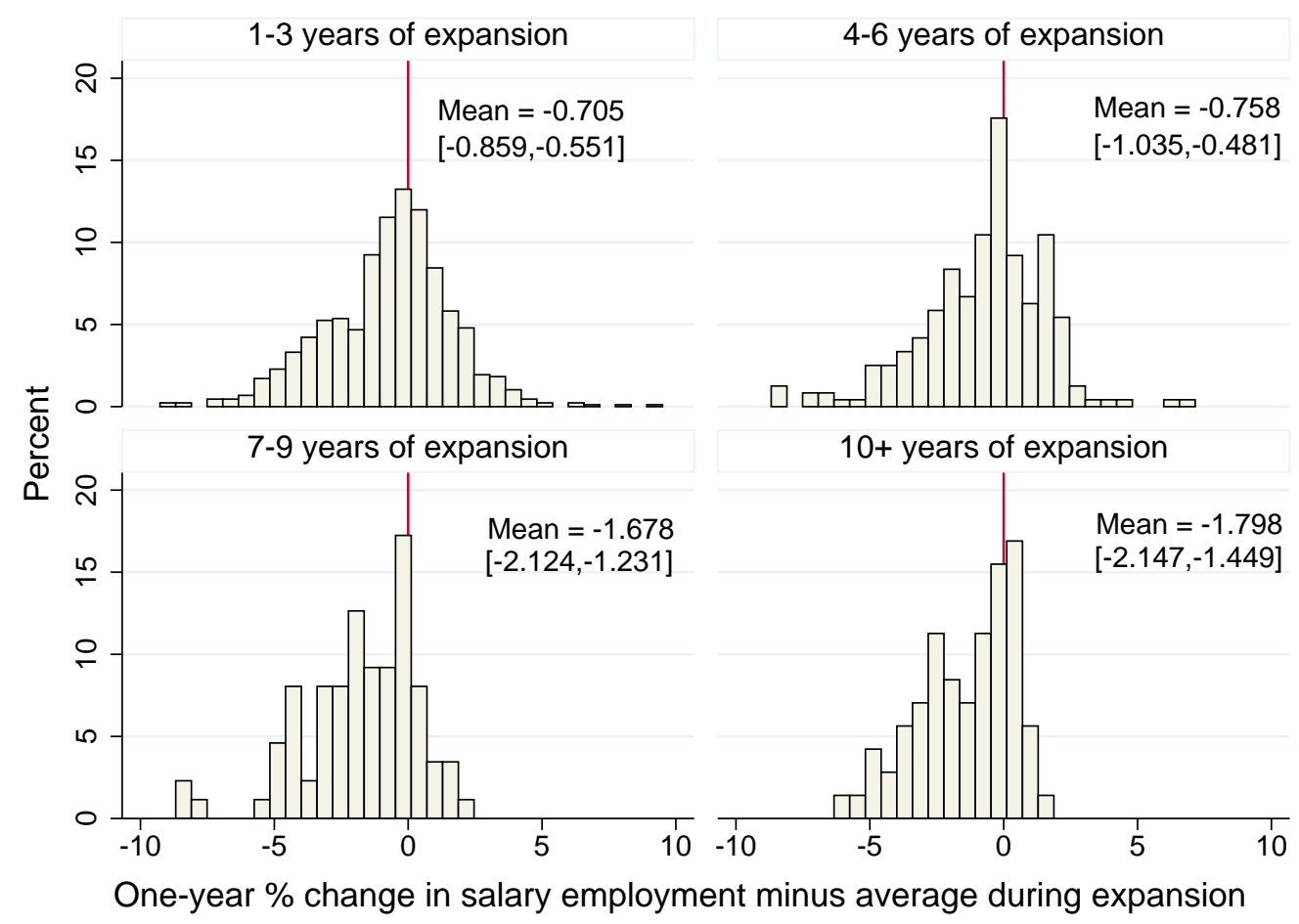

Figure 1: Histogram of the deviation in job growth from its expansion average for different durations of expansion for the 1273 crises identified in the Bureau of Economic Analysis regional level data, reporting mean and 95\% confidence interval of the mean. (See Section 4 for more detail.)

search frictions and also that workers are be hired to longer-term contracts. This occurs for several well documented reasons (e.g., see Farber (1999)) including that workers may have to invest in firm-specific human capital which requires long term contracts to avoid hold-up problems, and that workers may be more risk averse than firms in facing the search frictions in the labor markets and so optimal risk sharing involves long-term contracting.2 We take the search frictions as given, but the effects of the model could be even further amplified if we also allowed for effects such as that of the Beveridge Curve (Dow and Dicks-Mireaux $(1958)$ ), noting that the available labor pool becomes even tighter as the economy grows, giving more incentives for firms to accept worse matches.

Given these ingredients, the longer there is strong demand, the more bad matches will build up in an economy. This occurs even if firms are fully aware that a recession will eventually occur. In our model an eventual recession comes due to a random demand shock, but could also come due to a (small) productivity shock. Once the recession hits, the higher the fraction of bad matches that have built up (i.e., the longer it has been since the last

\footnotetext{
${ }^{2}$ It is not essential that the contract be indefinite, simply that there be some cost or friction to firing workers - so that contracts are not completely at will.
} 
recession), the worse the recession. $?^{3}$ Thus, the model produces patterns that exhibit the same patterns as those in Figure 1 .

Beyond providing new insights about the relationship between the length of an expansionary period and the subsequent depth and probability of recessions, there are other aspects of our model and empirical findings that we emphasize.

First, is that the depth of the recession is not being driven by the size of some productivity shock: it comes from the accumulation of poor matches in the economy and a normal shock. Thus, one does not need unusually rare or large shocks to get a large effect; this follows simply from a long expansion.

Second, although for the purposes of modeling, we focus on labor as the input that the firms hire, the same analysis extends to any input that has some scarcity and cost of search: for instance a firm might have a choice of using an old inefficient technology or upgrading to a new technology at some cost or delay. In a period of high demand, the firm may find it optimal to continue to use the inefficient technology and only change when demand becomes low. Thus, over expansionary periods inefficient technology and assets may accumulate, leading to larger downfalls when a negative shock finally hits the economy.

In terms of relationships to the literature, our approach is loosely related to the vast literature on labor search by workers (and firms) initiated by Diamond (1981; 1982a; 1982b), Mortensen (1982a; 1982b; 1999), and Pissarides $(1984 ; 1985 ; 2000)$. That literature includes recent works examining cyclical aspects of matchings, as in Jovanovic (1987), Barnichon (2010), Barnichon and Figura (2011), Furlanetto and Groshenny (2012), Michaillat (2012). In our analysis we abstract completely away from workers' decisions and focus solely on firms' hiring decisions. That provide us with new insights into the buildup of poor matches in employment over time that have not appeared in the literature before and are the driving force behind our results.

Ours is not the first work to provide foundations for, or evidence of, counter-cyclical exits. For example, an important paper by Bergin and Bernhardt (2008) is probably the most closely related and it provides new theory and insights into how firms' decisions based on productivity in the face of demand states lead to weaker firms staying in when demand is high and then exiting when demand becomes low. Also related is recent work by Berger (2011). His model involves firms allowing productivity to drop in good times and then restructuring during bad times. Our model differs in many aspects from both of these, but shares basic features as it is primarily driven by firms' decisions based on their productivity and the demand state and projections of future profits. Thus, for instance, our model also exhibits features of the counter-cyclical labor productivity that Berger analyzes. The novelty in our work comes on two dimensions: first, providing a theory predicting that the size of a recession and the number of layoffs will be positively related to the length of the expansion since the last recession (our "forest-fire" analogy), and second providing empirical

\footnotetext{
${ }^{3}$ The analogy to a forest fire is clear: in a healthy growth phase a forest can sustain the growth of weaker plants and high-fuel plants. The longer it has been since the last fire, the greater the accumulation of "underbrush" and fuel and the hotter and more extensive the subsequent fire when it finally appears.
} 
observations that are consistent with this theory.

\section{A Simplified Model}

We begin with a simplified model that illustrates some of the main points. In the simplified model the employment matches are either "good" or "bad" and the demand state is independent of employment. In Section 3, we present a richer model with any compact set of match types and interactions between demand and employment that provides additional insights and shows that these results are robust.

\subsection{Search and Hiring Decisions}

A firm can employ one worker at a time. $4^{4}$

Time comes in discrete periods $t \in\{1,2, \ldots\}$.

If the firm does not currently have a worker, then the firm gets to interview a potential new worker. The firm either decides to employ the worker, or to wait and search again. If the firm refuses the worker then the firm earns 0 profit for that period and awaits a new match in the next period.

The firm hires the worker indefinitely. This can be justified in several standard ways. One is that the worker is risk averse and there are some frictions to re-matching, in which case if the firm is less risk-averse than the worker then having a contract for more than one period is optimal. Another is that working for the firm may involve an up-front investment in firm-specific human capital and so offering a long-term contract provides efficient investment incentives and solves a hold-up problem (e.g., see Farber (1999)). For our analysis what is important is that workers are hired for more than one period at a time, and to keep the model uncluttered we impose this directly as it is clear that a variety of complications to the model would imply it.

Workers quit randomly with a probability $q \in[0,1]$ at the beginning of any period (excluding the period in which they are first hired).

There is a state of demand, either high or low, denoted $d_{t} \in\{H, L\}$. For the one-firm case, we take this to be independently and identically distributed across periods, being $H$ with probability $p$ and $L$ with probability $(1-p)$. We endogenize demand in later sections.

The match between the firm and the worker in period $t$ is either "good" or "bad," denoted $m_{t} \in\{G, B\}$, and stays for all periods for which a given worker works for the firm. The type of a match is good with probability $v$, bad with probability $(1-v)$.

\footnotetext{
${ }^{4}$ The extension to many workers is straightforward and one can simply combine several of our firms, with some minor complications if one allows for complementarities in workers. As there is little insight gained from having larger firms in this model, we work with the simplest case that highlights the employment decisions and effects.
} 
The consequence of the quality of the match is in terms of the profits of the firm, which depend on the state of demand and quality of the match, denoted $\pi_{d m}$, and satisfy the following:

- profits from good matches are positive regardless of the state, $\pi_{H G}>\pi_{L G}>0$;

- profits from bad matches are only positive in the high demand state, $\pi_{H B}>0>\pi_{L B}$; and

- good matches are more profitable than bad matches in each demand state $d, \pi_{d G}>\pi_{d B}$.

Note that we abstract away from modeling wages explicitly and simply roll them into profits directly. Effectively, any model of setting wages works, provided that the profits from hiring good matches exceeds that of bad matches, and that bad matches are only profitable in the high demand state.

Also, the quality of the match may be interpreted in different ways. It might be some idiosyncratic matching: does the personality worker fit well with the culture of the firm. It could be a basic match of skills: does a programmer know how to program in the appropriate software language. It could also be that some workers are simply more talented than others. The precise form of the quality of the match is not consequential: what is important is that the firm can end up with workers of greater or lesser productivity and that there is some randomness in that matching.

The firm discounts the future at a rate $\delta<1$ and maximizes its expected stream of discounted profits.

The worker takes a job regardless of the quality of the match.

The firm knows the quality of the match and the state when deciding on whether to hire a worker.

So, the ordering within a period is as follows:

- At the beginning of the period, a worker who was employed last period quits with probability $q$.

- Next, demand and match states are realized and observed by the firm (the match state is only relevant if the firm has a vacancy and a new match arrives).

- Then, the firm makes a hiring decision if it has a vacancy and a match is available.

- Finally, profits are recorded.

\subsection{A Single Firm's Hiring Decisions}

When a firm has an opening and a match is possible it must choose whether to hire this new match. 
Consider a period $t$ in which the firm has an opening, a match $m_{t}$ is possible and the realization of the state of demand is $d_{t}$. In an optimal strategy, the firm will clearly hire a good match regardless of the state. It is possible that in an optimal strategy, the firm would hire a bad match. In this simple version of the model, the firm would only choose to hire a bad match in a high demand state.

Therefore we consider two strategies: $\sigma \in\left\{\sigma_{g}, \sigma_{H b}\right\}$ where $\sigma_{g}$ means that a firm only hires good matches and hires them regardless of the demand state, and $\sigma_{H b}$ means that a firm hires good workers in any demand state and bad workers only in high demand states.

Let $V(\sigma)$ be the expected stream of discounted profits, beginning at the start of a period with a vacancy to be filled, and following a strategy $\sigma$. Straightforward calculations (details appear in Appendix 6.1) show that

$$
\begin{aligned}
V\left(\sigma_{g}\right) & =\frac{v E_{d}\left(\pi_{d G}\right)}{(1-\delta)(1-\delta(1-q)(1-v))} \\
& \text { and } \\
V\left(\sigma_{H b}\right) & =\frac{v E_{d}\left(\pi_{d G}\right)+p(1-v)\left(\delta(1-q) E_{d}\left(\pi_{d B}\right)+(1-\delta(1-q)) \pi_{H B}\right)}{(1-\delta)(1-\delta(1-q)(1-(v+p(1-v))))} .
\end{aligned}
$$

The following proposition then follows from the expressions for the value functions above.

Proposition 1 Hiring bad matches in high demand states is an optimal strategy if and only if

$$
\frac{v E_{d}\left(\pi_{d G}\right)}{1-\delta(1-q)(1-v)} \leq \frac{\pi_{H B}}{\delta(1-q)}-\left(\pi_{H B}-E_{d}\left(\pi_{d B}\right)\right)
$$

While this expression may be hard to interpret directly, the comparative statics are intuitive.

COROLlary 1 Hiring bad matches in a good state is more attractive relative to not doing so (i.e., the left hand side of (3) decreases and or the right hand side increases) as:

- good matches become less likely (v decreases),

- the firm becomes less patient ( $\delta$ decreases),

- workers quit with higher probability (q increases),

- profits from good matches (in either state) decrease ( $\pi_{d G}$ for either $d$ decreases), and

- profits from bad matches (in either state) increase ( $\pi_{d B}$ for either $d$ increases). 


\subsubsection{Firm-Level Crises}

Let a "firm crisis" be a situation in which there is low demand and the firm has a bad match in place: $d_{t}=L, m_{t}=B$.

Proposition 2 Suppose that (3) holds, so that a firm is willing to hire a bad match in the high demand state. Consider starting at some date $t$ with high demand $H$ and a good match $m_{t}=G$ and then consider $\tau$ subsequent periods of high demand. The probability that $m_{t+\tau}=B$ increases with $\tau$, and so the probability of a firm crisis occurring in period $t+\tau+1$ also increases in $\tau$.

Proposition 2 shows that firms are increasingly likely to have a firm crisis the longer the expansionary period before a low demand shock. The intuition is that the firm is more likely to have been forced to replace a worker the longer the duration of expansion, and hence the more likely the firm is to have hired a bad match ${ }^{5}$

\subsubsection{Waiting for Matches}

In the above model, whenever the firm has a vacancy it gets a new match and can hire the worker. The only friction is that it must wait a period to get a new match if it does not hire the current match. Another possible consideration is that it might take some (random) time for the firm to even get a new match. By allowing a vacancy to persist, a third type of strategy can become attractive in extreme cases: it can even be worthwhile to hire a bad match in a low demand state. In a labor market where workers are very scarce, then hiring a bad match in a low demand state incurs a temporary loss in profits, but then possibly a long-term expected profit, while not hiring the worker might lead to many periods, including high demand ones, without any worker.

This is not a main point of the paper, but something worth noting, so we show that it is possible and then proceed.

Modify the above model so that when a firm has a vacancy a possible match arrives with probability $\alpha \in(q, 1] .^{6}$ If the firm refuses the worker then the firm earns 0 profit for that period and awaits a new match in the next period, which again arrives with probability $\alpha$.

There are now three strategies that could be optimal hiring strategies: $\sigma \in\left\{\sigma_{g}, \sigma_{H b}, \sigma_{a}\right\}$, where $\sigma_{g}$ means that a firm only hires good matches and hires them regardless of the demand state, and $\sigma_{H b}$ means that a firm hires good matches in any demand state and bad matches only in high demand states; and $\sigma_{a}$ means that a firm hires any match when it has a vacancy regardless of the demand state.

\footnotetext{
${ }^{5}$ The probability of having a bad match in place asymptotes upward towards the steady-state probability that a firm would have a bad match in place if the demand was always high.

${ }^{6}$ Requiring $\alpha>q$ ensures that the long-run steady state of the economy with multiple firms (see Section 2.3 features positive employment.
} 
Straightforward calculations show that (details are provided in Appendix 6.1):

$$
\begin{aligned}
V\left(\sigma_{g}\right) & =\frac{\alpha v E_{d}\left(\pi_{d G}\right)}{(1-\delta)(1-\delta(1-q)(1-\alpha v))} \\
V\left(\sigma_{H b}\right) & =\frac{\alpha v E_{d}\left(\pi_{d G}\right)+\alpha p(1-v)\left(E_{d}\left(\pi_{d B}\right)+(1-\delta(1-q))\left(\pi_{H B}-E_{d}\left(\pi_{d B}\right)\right)\right)}{(1-\delta)(1-\delta(1-q)(1-\alpha(v+p(1-v))))} \\
V\left(\sigma_{a}\right) & =\frac{\alpha v E_{d}\left(\pi_{d G}\right)+\alpha(1-v) E_{d}\left(\pi_{d B}\right)}{(1-\delta)(1-\delta(1-q)(1-\alpha))}
\end{aligned}
$$

If $\alpha=1$, then the expressions in (4) and (5) reduce to (1) and (2), respectively. Moreover, in that case, it is easy to check that $V\left(\sigma_{H b}\right)>V\left(\sigma_{a}\right)$ (hiring a bad worker in a low demand state is dominated by waiting).

From these expressions, we see that if $\alpha$ is sufficiently low, it is possible to have hiring any match in any state be the optimal strategy (so that $V\left(\sigma_{a}\right)$ is the maximum of the above three expressions). $]^{7}$

Moreover, the comparative statics results from Corollary 1 still hold when comparing $V\left(\sigma_{g}\right)$ and $V\left(\sigma_{H b}\right)$, and $\alpha$ has the same effect as $v$ : hiring bad workers is more convenient in situations where the rate of arrivals of possible matches is lower.

\subsection{Multiple Firms}

We now examine what happens on the economy level, considering multiple firms making decisions. The interest in this case comes from two angles. One is that the interaction between firms may affect their profitability. The other is that the demand state can depend on overall employment.

We first analyze interaction between firms and then discuss the combination of the two effects.

We work with a unit measure of atomless firms so that a firm does not anticipate its individual hiring decision influencing economy-wide dynamics.

At any point in time, each firm is in one of three match states: $G, B, U$ where $U$ means that they are currently unmatched. The relevant match state of the economy is $g_{t}, b_{t}, u_{t}$, which is the fraction of firms that have each type of match at the beginning of period $t$, and where $u_{t}=1-g_{t}-b_{t}$. Thus, it is sufficient to keep track of $g_{t}, b_{t}$.

\subsubsection{Interaction in Firm Failure Rates}

This version of the model is the same as the single-firm case except for the following. Firms interact with each other. In a high demand state, all firms keep their workers. In an low demand state, some firms with bad matches can be forced to layoff their workers.

\footnotetext{
${ }^{7}$ This is easily seen by noting that the denominators all converge to $(1-\delta)(1-\delta(1-q))$ as $\alpha \rightarrow 0$, and then the ordering on the numerators is a comparison between $v E_{d}\left(\pi_{d G}\right)+(1-v) E_{d}\left(\pi_{d B}\right)$ using $\sigma_{a}, v E_{d}\left(\pi_{d G}\right)$ using $\sigma_{g}$, and $v E_{d}\left(\pi_{d G}\right)+p(1-v)\left(E_{d}\left(\pi_{d B}\right)+(1-\delta(1-q))\left(\pi_{H B}-E_{d}\left(\pi_{d B}\right)\right)\right)$. The first expression is larger than either of the others if $\pi_{H B}-E_{d}\left(\pi_{d B}\right)$ is not too large.
} 
We refer to this a "failure" and say that the firm "fails", and treat this as if the firm disappears and is replaced by a new firm. If anything, this tempers the results as it makes firms more reluctant to hire bad matches. It slightly simplifies some of the calculations.

In particular, we consider settings in which a firm is more likely to be forced to layoff its worker as the fraction of bad matches $\left(b_{t} /\left(g_{t}+b_{t}\right)\right)$ increases. So, as the overall productivity in the economy decreases, individual firms are more susceptible to failure.

We let the probability that a given firm with a bad match fails in a low demand state be given by $\phi\left(\frac{b_{t}}{g_{t}+b_{t}}\right)$, where $\phi$ is a non-decreasing function.

A simple example of this is one in which firms are paired together, for instance in some business venture, or have a vertical relationship in which one supplies the other. If two firms with bad matches are paired and the state is $L$, then they both lose their worker and shut down. For instance, low demand causes lower sales for a retailer, which then affects a supplier to that retailer, and if both have bad worker matches, they each suffer to the point of having to shut down and layoff their workers. Other pairs survive (subject to the usual quitting constraints). For simplicity, we can assume entry of firms in order to have the mass of active firms constant and equal to one.

This interaction between firms corresponds as captured in $\phi$ to a situation in which firms are complements. This comes both from direct interactions as well as interactions with the whole economy: firms fail with a higher rate as the overall health of firms in the economy is weaker. The alternative situation would be one where weak firms benefit from others' weaknesses. Although this may seem intuitive, fewer firms tend to be in direct competition than in some other relationship. In fact, as pointed out by Acemoglu and Autor (2010) the complements case seems more relevant 8

In fact, it is not necessary to have firms failures be positively correlated for our results to hold - it is only necessary that they are not too negatively correlated. Firms will tend to want to hire bad matches in high demand states, and all that is necessary is that this tendency not be overly counter-acted.

In this setting, the firms' hiring decision are more complicated since they care about their interactions with other firms, and hence condition their decisions on the match state $g_{t}, b_{t}$ in addition to the demand state. Firms can still be willing to hire bad matches in high demand states, regardless of the match state.

So, for the following two results we analyze a situation in which firms hire bad matches in a high demand state, regardless of the current state of the matches in the economy, but do not hire bad matches in a low demand $L$ state. This holds for a range of parameter values. Also, we assume that the initial match states, $b_{0}$ and $g_{0}$, are below their maximum

\footnotetext{
${ }^{8}$ For example, as they point out, Ford Motor Company lobbied the U.S. Congress to help bail out General Motors, since they share many parts suppliers. If G.M. had failed that would have hurt the suppliers and the loss of suppliers would have hurt Ford more than they would gained from having lost a competitor in the car market.
} 
steady-state levels..$^{910}$

Proposition 3 Consider an economy emerging from a recession at some time $t$ in a low demand state with a ratio of bad matches that is not excessively high, $\frac{b_{t}}{g_{t}}<\frac{1-v}{v}$. Consider $\tau$ subsequent expansionary periods of high demand. The longer the expansionary period lasts (the greater is $\tau$ ):

(a) the higher total employment, $g_{t+\tau}+b_{t+\tau}$,

(b) the higher the total number of bad matches and the fraction of bad matches, $b_{t}$ and $b_{t} /\left(g_{t}+b_{t}\right)$, and

(c) the higher both the number and fraction of firms that fail in the next low demand state (the larger the recession and the more contagion in the recession).

Proposition 3 shows that the dynamics that occur on a single firm basis extend to a whole economy. In fact, not only do firms have higher probabilities of failing, but higher factions and numbers of firms fail the longer the expansionary period.

In addition to what happens at the onset of a recession, we can also deduce some dynamics within recessions (consecutive periods with low demand states).

Proposition 4 Consider a recession (consecutive sequence of low demand states):

(d) the longer the recession lasts, the lower the number and the fraction of firms that fail per period,

(e) the longer the recession lasts, the higher both the fraction and mass of good matches in the economy.

To see the intuition behind (d) and (e), note that there are two forces increasing the fraction of matches that are good, $g /(g+b)$. The first is the elimination of bad matches through accumulated failures, and second is that that vacancies are only filled with good matches in low demand states. This leads to a decreasing failure rate as only the strong survive, which also leads to fewer failures of remaining bad matches.

\footnotetext{
${ }^{9}$ The economy has two steady-state levels, one that would be reached if demand stayed high forever (this is the maximum for $b$ ), and another if there was low demand forever (the maximum for $g$ ).

${ }^{10}$ The proofs in Appendix 6.1 are written for the more general case with random arrival of possible matches at rate $\alpha \in(q, 1]$, as discussed in Section 2.2 .2 .
} 


\subsubsection{Employment Dependent Demand}

We now enrich the model so that the evolution of the demand state, $d_{t}$, can depend on on the employment levels, $g_{t}, b_{t}$. Higher levels of employment (in the partial ordering on $g_{t}, b_{t}$ ) leads to a higher probability of high demand $H$. The idea is that higher employment of both types of matches leads to higher demand: more workers have wages to spend. This leads to a definition of the "overheating" of an economy.

Consider a setting that begins with the employment states, $g_{t}$ and $b_{t}$, both below the steady-state levels that they would reach if high-demand states persisted forever. The more periods that occur without a low demand state, the higher the employment, which leads to higher probabilities of staying in the high demand state, which then leads to more bad matches hired: providing more fuel for a deeper and longer recession when it hits.

In particular, let the probability of a high demand state be an increasing function of the total number of employed workers. Let $\bar{e}$ be a threshold such that if $g_{t}+b_{t}<\bar{e}$ then only good matches are hired, but once $g_{t}+b_{t} \geq \bar{e}$ then it is attractive to hire bad matches in the high demand state, since then there is a high enough probability that the next periods will be high demand as well.

Periods of high demand that we refer to as expansions consist of two subsequent phases: Slow expansion: $g_{t}+b_{t}<\bar{e}$ and only good matches are hired. The transition here is

$$
\begin{aligned}
g_{t+1} & =(1-q) g_{t}+v \alpha\left(q\left(1-u_{t}\right)+u_{t}\right) \\
b_{t+1} & =(1-q) b_{t} \\
u_{t+1} & =(1-v \alpha)\left(q\left(1-u_{t}\right)+u_{t}\right)
\end{aligned}
$$

Fast expansion, an "overheating" economy: bad matches are hired and the process is reinforcing, meaning that total employment keeps growing as the probability of low demand keeps falling. The transition here is described in equations (7), (8), and (9) in Appendix 6.1.

If the economy starts with total employment below the threshold level $\bar{e}$, the economy will start with a slow expansion during which employment grows at a slow rate, eventually followed by a faster expansion once total employment reaches $\bar{e}$. The gravity of a new recession is low during the adjustment phase, and then grows the longer the expansion.

\section{A General Model}

We now generalize the above model to allow for many possible match types and demand states.

\subsection{The Setting}

An economy consists of a unit mass of non-atomic firms. 
The set of demand states comes from a compact metric space $D$ with an associated partial ordering $\geq$. This allows demand to be multi-dimensional, so that demands can differ across sectors.

The set of possible match types for any firm lies in a compact set $M \subset \mathbb{R}$.

The match state in the economy at time $t$ is described by $\left(u_{t}, \mu_{t}\right)$, where $u_{t} \in[0,1]$ is the fraction of firms with a vacancy and $\mu_{t}$ a probability distribution on $M, \mu_{t} \in \mathcal{P}(M)$, which describes the relative frequencies of types of matches among firms that have workers.

The timing of period $t$ is the following:

1. Demand realization: A demand state $d_{t}$ is drawn from the distribution $\eta \in \mathcal{P}(D)$ and publicly observed.

2. Failures/Layoffs: A firm matched with a worker of type $m$ "fails," i.e., shuts down and loses the worker, with probability $\phi\left(\mu_{t-1}, d_{t}, m\right)$, where $\phi: \mathcal{P}(M) \times \mathcal{D} \times M \rightarrow[0,1]$ is continuous and non-increasing in $\mu, d$, and $m{ }^{11}$

3. Job turnover: Remaining firm-worker matches are exogenously separated with probability $q \in[0,1]$

4. Hiring: Active firms with a vacancy can hire a new worker whose type is randomly drawn from the (non-atomic) distribution $F$.

5. Profits are recorded: An active firm matched to a type $m$ worker makes profits $\pi(m, d)$, where $\pi: M \times D \rightarrow \mathbb{R}$ is bounded and increasing in both arguments. An active firm without a worker has zero profits.

6. Entry: The measure of firms that have failed attracts an equal mass of new firms in the economy, these become active with an open vacancy. 13

The new state $u_{t}, \mu_{t}$ is publicly observed.

Firms maximize the discounted sum of expected profits over time with a discount factor $\delta \in(0,1)$.

\subsection{Monotonicity and Stationary Strategies}

A history of the economy through period $t$ is an array

$$
h_{t}=\left(u_{t-k}, \mu_{t-k}, d_{t-k}\right)_{k=0}^{t} .
$$

\footnotetext{
${ }^{11}$ We endow $\mathcal{P}(M)$ with the weak*-topology and the first-order stochastic dominance partial order.

${ }^{12}$ We could fold natural turnover into the layoffs that are dependent on the state, but it is easy to separate the two - so this corresponds to the lowest, base rate of separation that occurs regardless of the state of demand and matches, while the state-sensitive part of the separation is captured above.

${ }^{13}$ This keeps the mass of firms in the economy constant and equal to one. Alternatively, we could simply have bankrupt firms begin anew, with a loss from going bankrupt.
} 
Because firms are non-atomic, the decision of a single firm does not affect the transition of the employment state $u_{t-1}, \mu_{t-1} \rightarrow u_{t}, \mu_{t}$ or the demand state $d_{t} \rightarrow d_{t+1}$. Thus, a firm's future expected payoffs are increasing in its hired match-type $m$ : for any (end of) period in which a firm has a worker, the firm's profit, $\pi(m, d)$, is increasing in $m$ and its probability of transitioning to bankruptcy is non-increasing in $m$ given any $u, \mu$ and $d$.

Maximization of expected discounted streams of profits implies that in any given period $t$, and for any history $h_{t}$, a firm has a threshold $\widehat{m}_{t}\left(h_{t}\right) \in M$ such that a match is hired if it exceeds $\widehat{m}_{t}\left(h_{t}\right)$ and not if it is below. The firm may mix at atoms, but regardless, this allows us to represent a strategy for firm in terms of the probability of hiring during a given period.

So, a strategy $\sigma\left(h_{t-1}, d_{t}\right) \in[0,1]$ indicates the probability that a firm hires a match conditional on the history through the previous history and the current demand state.

In this setting, an equilibrium exists in stationary strategies, allowing decisions in period $t$ to depend only on the current-period state $\left(u_{t-1}, \mu_{t-1}, d_{t}\right)$.

\subsection{Equilibrium}

When the other firms in the economy adopt a given strategy, $\sigma$, a firm (being atomless) then faces the transition $\mathbf{T}^{\sigma}$ describing the evolution of the state $\left(u_{t-1}, \mu_{t-1}, d_{t}\right)$ and chooses its strategy optimally 14

An equilibrium is a function $\sigma^{*}$ such that 15

1. $\sigma^{*}$ is optimal (among all strategies, including non-stationary ones) for all histories and states for a firm taking $\mathbf{T}^{\sigma^{*}}$ as given

2. $\mathbf{T}^{\sigma^{*}}$ is generated by $\sigma^{*}$ (and the other elements of the model).

In this model an equilibrium exists, as shown in Appendix 6.2 16

THEOREM 1 There exists an equilibrium $\sigma^{*}$, and any equilibrium is such that the hiring strategy $\sigma^{*}\left(u_{t-1}, \mu_{t-1}, d_{t}\right)$ is non-decreasing in the demand state $d_{t}$.

The assumptions are weak enough so that there may exist multiple equilibria, but our results apply to directly to any equilibria that satisfy minimal conditions discussed below.

\footnotetext{
${ }^{14}$ The function $\mathbf{T}^{\sigma}$ also depends on the failure function $\phi$, the distributions $F$ and $\eta$, and the parameter $q$ as detailed in Appendix 6.2 We omit the full notation to keep the presentation uncluttered.

${ }^{15}$ This definition of equilibrium allows for a continuum of agents and circumvents some measurability assumptions by allowing the measures to aggregate the individual actions in an anonymous manner given the atomless nature of the setting. This is a standard technique, which dates to Hildenbrand (1974) and has been extended and used in a variety of settings, including Bodoh-Creed (2012) and Adlakha et al. (2011).

16 Bergin and Bernhardt (1992) prove existence of equilibria in a class of related dynamic models, but their results would not apply to our model without stronger assumptions. Thus, we provide a direct proof of existence tailored to our model.
} 


\subsection{Dynamics}

We now analyze the dynamics of the employment state and failures in an equilibrium.

One condition that is needed for the more general model to exhibit dynamics similar to those we identified in the simple model, is that the match state of the economy does not overly feedback to reverse decisions by firms. In particular, consider a firm deciding on whether to hire a low match. For worse overall match states of the economy, the firm is less prone to want to hire that match, since a lower match state could lead to a worse recession once it comes, which makes the firm less likely to survive the recession. This effect cannot be so overwhelming that it reverses the state of the economy so that the economy emerges with better matches. In particular, we work with the following "no reversal" condition.

An employment state $u, \mu$ dominates another employment state $u^{\prime}, \mu^{\prime}$ if $u \geq u^{\prime}$ and $\mu$ (weakly) first order stochastic dominates $\mu^{\prime}$.

Domination implies that there are both absolutely and relatively more "bad" matches under $u^{\prime}, \mu^{\prime}$, since the distribution is worse and there is higher employment. We say that there is strict dominance if both inequalities are strict ${ }^{17}$

An economy and a strategy $\sigma$ satisfy no reversals if $u_{t-1}, \mu_{t-1}$ dominates $u_{t-1}^{\prime}, \mu_{t-1}^{\prime}$ implies that $u_{t}, \mu_{t}$ dominates $u_{t}^{\prime}, \mu_{t}^{\prime}$ for any $d_{t}$, where $u_{t}, \mu_{t}=\mathbf{T}^{\sigma}\left(u_{t-1}, \mu_{t-1}, d_{t}\right)$ and $u_{t}^{\prime}, \mu_{t}^{\prime}=$ $\mathbf{T}^{\sigma}\left(u_{t-1}^{\prime}, \mu_{t-1}^{\prime}, d_{t}\right)$.

A variety of conditions are sufficient for this to hold, such as $\sigma$ not depending on $u_{t-1}, \mu_{t-1}$ as in the simple model.

As in the model analyzed in Section 2 , the duration of an expansionary period decreases the overall quality of employed matches and increases the fraction of firms going bankrupt for a given drop in the demand-state $d$. In this richer environment, moreover, the size of the expansion (in terms of increases in demand) has a similar effect, since equilibrium hiring $\sigma^{*}(u, \mu, d)$ is non-decreasing in $d$.

Consider $t$ periods, with corresponding demand states $\mathbf{d}=\left(d_{1}, \ldots, d_{t}\right)$ and some starting employment state $u_{1}, \mu_{1}$. Given some threshold strategy $\sigma$, let $M_{t}^{\sigma}\left(u_{1}, \mu_{1}, \mathbf{d}\right)$ be the employment state $u_{t}, \mu_{t}$ in the economy in period $t$ conditional on the starting employment state and the sequence of demands $\left(u_{1}, \mu_{1}, \mathbf{d}\right)$.

PROPOSITION 5 Consider an economy and equilibrium $\sigma^{*}$ that satisfy no reversals with starting employment state $u_{1}, \mu_{1}$. If $\mathbf{d}^{\prime}=\left(d_{1}^{\prime}, \ldots, d_{t}^{\prime}\right)<\mathbf{d}=\left(d_{1}, \ldots, d_{t}\right)$, then $M_{t}^{\sigma^{*}}\left(u_{1}, \mu_{1}, \mathbf{d}^{\prime}\right)$ dominates $M_{t}^{\sigma^{*}}\left(u_{1}, \mu_{1}, \mathbf{d}\right)$.

The following corollary then shows that the fraction of firms going bankrupt is increasing in the history of demand states, so that a higher sequence of demands has led to worse matches and hence more failures for any given circumstance in the next period.

\footnotetext{
${ }^{17}$ Strict first order stochastic dominance here means that the two distributions differ and satisfy weak dominance.
} 
COROLlary 2 Consider an economy and equilibrium $\sigma^{*}$ that satisfy no reversals, starting employment state $u_{1}, \mu_{1}$, and a sequence of $t$ periods with demand states $\mathbf{d}$. The fraction of firms failing for a given demand state $d_{t+1}$ in the next period is increasing in $\mathbf{d}$.

Our next results show that the longer the time horizon, the worse the expected employment state, and the more firms that are expected to fail.

Consider an initial demand state $d_{1}$, and let

$$
G_{t}\left(d_{1}\right)=\left\{\left(d_{1}, \ldots, d_{t}\right) \in D^{t}: d_{\tau+1} \geq d_{\tau}, \tau=1, \ldots, t-1\right\}
$$

be all the possible $t$-period expansions, so that demand increases for those $t$ periods.

Given some threshold strategy, $\sigma$, and some initial employment state, $u_{1}, \mu_{1}$, let

$$
E M_{t}^{\sigma}\left(u_{1}, \mu_{1}, d_{1},\right)=E\left[M_{t}^{\sigma}\left(u_{1}, \mu_{1}, \mathbf{d}\right) \mid \mathbf{d} \in G_{t}\left(d_{1}\right)\right]
$$

be the expected employment state in the economy in period $t+1$ conditional on $\left(u_{1}, \mu_{1}, G_{t}\left(d_{1}\right)\right)$.

Proposition 6 Consider an economy and equilibrium $\sigma^{*}$ that satisfy no reversals and initial employment and demand states, $u_{1}, \mu_{1}, d_{1}$. The expected employment state conditional on $t$ periods of expansion, $E M_{t}^{\sigma^{*}}\left(u_{1}, \mu_{1}, d_{1}\right)$, is weakly decreasing in the number of periods, $t$, in our dominance sense.

COROLlary 3 Consider an economy and equilibrium $\sigma^{*}$ that satisfy no reversals, and starting employment and demand states, $u_{1}, \mu_{1}, d_{1}$. The longer the expansion (the greater the number of increasing demand periods $t$ ), the larger the expected fraction of firms that fail for any given demand state $d_{t+1}$.

\section{Empirical Observations}

We now present some empirical findings that are consistent with our theoretical results. We use the 179 Bureau of Economic Analysis (BEA) Economic Areas as the relevant markets (as in our model within a given area firms interact with each other and share the same demand and labor market) ${ }^{18}$ We find a significant negative relationship between the duration of an expansion and the subsequent drop in the number of wage and salary jobs at the onset of a crisis.

\footnotetext{
${ }^{18}$ To quote, these correspond to the "relevant regional markets surrounding metropolitan or micropolitan statistical areas. They consist of one or more economic nodes, metropolitan or micropolitan statistical areas, that serve as regional centers of economic activity and the surrounding counties that are economically related to the nodes. These economic areas represent the relevant regional markets for labor, products, and information. They are mainly determined by labor commuting patterns that delineate local labor markets and that also serve as proxies for local markets where businesses in the areas sell their products."
} 


\subsection{BEA Economic Areas Crises (1969-2011)}

We use a balanced panel provided by the BEA covering the years 1969-2011, and containing for each area the complete yearly series of the area's population, number of wage and salary jobs, and proprietors' income.19

We define the onset of an (area-level) 'crisis' as the first year of negative growth of proprietors' income following one or more years of positive growth, which we refer to as an 'expansion'. This results in a dataset of 1273 crisis onsets for which we can compute the duration of the preceding expansions ${ }^{20}$

In Appendix 6.3 we show that the negative relationship between length of expansion subsequent loss of jobs is robust to alternative ways of defining a crisis, including various alternative definitions that consider a crisis to be either some absolute or some relative change in growth, rather than requiring that it become negative.

For each crisis we observe the growth rates of the population, the proprietors' income, and the number of wage and salary jobs (which we refer to as 'job growth' henceforth). We also keep track of average income and job growth rates during the expansionary period preceding the crisis. In terms of our model, proprietors' income is a measure of firms' profitabilities in the area, while the number of wage and salary jobs measures the number of workers employed by these firms.

Our model predicts that, ceteris paribus, a longer expansion should correspond to a bigger drop in job growth. This contrasts with a standard stationary environment, where the duration of the expansionary period preceding a crisis should not have any impact on the drop in employment in the first year of crisis after controlling for income and population growth.

We regress job growth in an area at the onset of a crisis on the expansion duration and various controls. Trending components are extraneous to our simple model with i.i.d. demand and a fixed population, but trends are evident in the data - especially in population movements. Thus, it is important to control for such trends, and so we control for the average job growth during the expansion years preceding the crisis in order to measure the impact of expansion's duration on the deviation of job growth from its existing trend. In the full specification, we also include state and year fixed effects. State fixed effects control for state-specific trends that might differ from the area specific average job growth during the preceding expansion. The impact of expansion's duration can be estimated by looking at areas entering a crisis in the same year (as the year fixed-effects control for year-specific US-wide shocks) after expansions with different durations.

In Table 1 we report the OLS estimates. The effect of duration is negative and significant

\footnotetext{
${ }^{19}$ The BEA definitions of wage and salary employment and proprietors' income can be found at http://www.bea.gov/regional/definitions/nextpage.cfm?key=Wage\%20and\%20salary\%20employment, and http://www.bea.gov/regional/definitions/nextpage.cfm?key=Proprietors\%20income, respectively. Data were last downloaded November $12^{\text {th }}, 2013$.

${ }^{20}$ Some crises happen near the beginning of the data set and so the full length of the expansion cannot be computed. Those are omitted from our calculations.
} 
in all the various specifications, with the coefficient varying between -0.03 and -0.06 . Roughly, 5 additional years of expansion implies an additional drop in job growth between .15 and .30 percent, everything else held constant. We compute robust standard errors clustered at the area level (thus allowing for arbitrary correlation of job growth within a given area).

Table 1: OLS regression. Robust standard errors, clustered at the area level.

\begin{tabular}{|c|c|c|c|c|c|c|}
\hline \multirow[b]{2}{*}{ Duration of Expansion } & \multicolumn{6}{|c|}{ Job Growth (onset of crisis) } \\
\hline & $\begin{array}{c}-0.036^{\star \star} \\
0.0171\end{array}$ & $\begin{array}{c}-0.040^{\star \star \star} \\
0.0142\end{array}$ & $\begin{array}{c}-0.033^{* *} \\
0.0169\end{array}$ & $\begin{array}{c}-0.039^{* *} \\
0.0161\end{array}$ & $\begin{array}{c}-0.039^{\star \star} \\
0.0161\end{array}$ & $\begin{array}{c}-0.061^{\star \star \star} \\
0.0170\end{array}$ \\
\hline $\begin{array}{l}\text { Avg. Job Growth } \\
\text { During Expansion }\end{array}$ & $\begin{array}{c}0.588^{\star * \star} \\
0.0413\end{array}$ & $\begin{array}{c}0.477^{* * *} \\
0.0351\end{array}$ & $\begin{array}{c}0.421^{* * *} \\
0.0359\end{array}$ & $\begin{array}{l}0.128^{* *} \\
0.0497\end{array}$ & $\begin{array}{c}0.135^{\star * \star} \\
0.0494\end{array}$ & $\begin{array}{l}0.045 \\
0.0663\end{array}$ \\
\hline $\begin{array}{l}\text { Population Growth } \\
\text { (onset of crisis) }\end{array}$ & & & & $\begin{array}{c}0.840^{* * *} \\
0.0727\end{array}$ & $\begin{array}{c}0.842^{\star \star \star} \\
0.0731\end{array}$ & $\begin{array}{c}0.819^{\star * *} \\
0.0950\end{array}$ \\
\hline $\begin{array}{l}\text { Avg. Propietors' } \\
\text { Income Growth } \\
\text { During Expansion }\end{array}$ & & & & & $\begin{array}{l}-0.001^{*} \\
0.0008\end{array}$ & $\begin{array}{c}-0.004^{* * *} \\
0.0003\end{array}$ \\
\hline Constant & $\begin{array}{l}-0.038 \\
0.1055\end{array}$ & $\begin{array}{l}1.264^{* * *} \\
0.5663\end{array}$ & $\begin{array}{l}1.120^{\star \star} \\
0.5254\end{array}$ & $\begin{array}{l}0.644 \\
0.1620\end{array}$ & $\begin{array}{c}2.217^{\star \star \star} \\
0.1984\end{array}$ & $\begin{array}{l}-1.069 \\
1.9212\end{array}$ \\
\hline $\begin{array}{l}\text { Obs. } \\
\text { FE } \\
\text { Years } \\
\text { R-squared }\end{array}$ & $\begin{array}{c}1273 \\
X \\
1969-2011 \\
0.262\end{array}$ & $\begin{array}{c}1273 \\
\text { Year } \\
1969-2011 \\
0.603\end{array}$ & $\begin{array}{c}1273 \\
\text { State, Year } \\
1969-2011 \\
0.647\end{array}$ & $\begin{array}{c}1273 \\
\text { State, Year } \\
1969-2011 \\
0.691\end{array}$ & $\begin{array}{c}1273 \\
\text { State, Year } \\
1969-2011 \\
0.692\end{array}$ & $\begin{array}{c}770 \\
\text { State X Year } \\
1969-2012 \\
0.890\end{array}$ \\
\hline
\end{tabular}

To see the effects graphically, in Figure 2 we plot the polynomial smoothing of estimated residuals of changes in job growth rate minus trend, when controlling for state and year fixed effects as well as population growth and change in income growth at the onset of the crisis. ${ }^{21}$ The shaded region is the $95 \%$ confidence interval with clustered standard errors.

The results in Table 1 follow a conservative specification. If the recent world-wide financial crisis is excluded (removing years past 2008) which caused systematic drops in job growth, then the coefficients go up significantly, as we see in Appendix 6.3. Moreover, one can directly work with deviations of growth from average (see Table 2 in the Appendix 6.3).

Another method of correcting for variations in trends is to work with a vector autoregressive (VAR) formulation. Such formulations result in very similar results, with even larger coefficients, as we report in Table 3 of Appendix 6.3 .

\section{Concluding Remarks}

We have found that the drop in job growth during an economic downturn is correlated with the length of the preceding expansionary period. This is observed when analyzing U.S. regional level data starting from 1969. We have provided a model of this in which firms facing

\footnotetext{
${ }^{21}$ These are the residuals of the regression corresponding to equation 20 in the appendix when restricting $\beta_{1}=0$.
} 
Figure 2: Polynomial smoothing of estimated residuals from a, plotted as a function of the expansion, $95 \%$ confidence intervals.

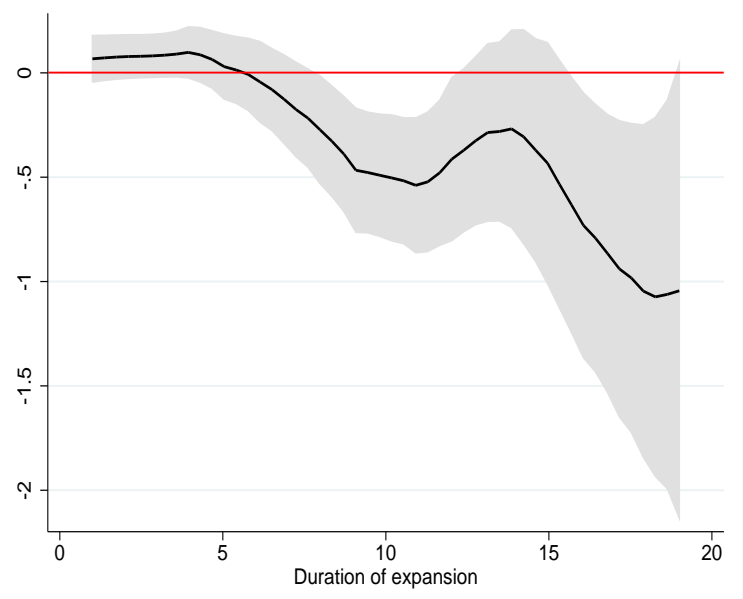

search frictions in hiring workers are willing to hire relatively lower-productivity matches in high demand periods. These lower-quality matches build up during an expansion, then leading to larger layoffs as an economy eventually hits a negative shock (without requiring a large shock to trigger a large downturn). This provides a basic and endogenous asymmetry in business cycles, and a fundamental form of non-stationarity. Although we have discussed this in terms of employment dynamics, it holds with any factor of production that is subject to medium to long-term investments, including various forms of capital and technologies.

\subsection{Policy Implications}

The findings here suggest that policies aimed at employment and business cycles should take such dynamics into account. Given the forest-fire analogy to our model, one is tempted to search for further analogies in terms of policies of controlled burns and not over-controlling small fires when they hit. We are wary of pushing the analogy to that extent.

Nonetheless, the model does have implications that are at least worth thinking through for further evaluation. In particular, lowering frictions in labor markets would lower the number of bad matches. More specifically, one tends to see two prominent ways of helping insure workers against unemployment. One is through regulations that make it difficult for firms to fire or lay off workers. Another is to provide various forms of unemployment insurance and assistance in searching for employment. In the context of our model, the second approach is superior to the first: increasing the rigidity increases the number of bad matches, while providing additional assistance smoothing transitions for workers allows them to be hired to more flexible contracts that eliminates the long-term build-up of bad matches ${ }^{22}$

\footnotetext{
${ }^{22}$ Note that this is an indirect effect: offering unemployment insurance changes the nature of employment contracts permitting greater turnover. This is aside from incentive effects it causes in the search decisions, which are also important (e.g., see Schmeider et al. (2012)).
} 


\subsection{Extensions}

Our analysis is a partial equilibrium one, as we do not model entry of firms or search decisions by workers. Although embedding our model into a fuller equilibrium setting would add complexity, it could also result in further amplification of some of the effects that we have documented. As workers become scarcer as an expansion endures, the available match quality may be further reduced further reinforcing the fraction of bad matches. Similarly, as more firms enter the market on the margin during an expansion, they would tend to be firms with worse productivity matches overall. This could be an interesting area for further analysis.

In our model we have folded wages into the profit function, since the explicit determination of wages is inconsequential for our results - just the overall resulting profit numbers. Nonetheless, it could be interesting to explore dynamic wage implications of an extended model that includes wage determination.

A last comment concerns on-the-job search. Allowing for such search could have countervailing effects. On the one hand it might lead some bad matches to find better matches over time. On the other hand, it might be that good matches are people who generally have better prospects and rematch more easily, leaving bad matches left behind at firms. Overall effects would require a rich model to disentangle and would be interesting to explore.

\section{References}

Acemoglu, D. And D. Autor (2010): "Skills, Tasks and Technologies: Implications for Employment and Earnings," Tech. Rep. 16082, NBER Working Papers.

Adlakha, S., R. Johari, and G. Weintraub (2011): "Equilibria of dynamic games with many players: existence, approximation, and market structure." mimeo: Stanford University.

BARnichon, R. (2010): "Productivity and unemployment over the business cycle," Journal of Monetary Economics, 57, 1013-1025.

Barnichon, R. And A. Figura (2011): "Labor Market Heterogeneities, Matching Efficiency, and the Cyclical Behavior of the Job Finding Rate," Mimeo, Universitat Pompeu Fabra.

Berger, D. (2011): "Countercyclical Restructuring and Jobless Recov," manuscript, Yale University.

Bergin, J. AND D. BernhardT (1992): "Anonymous sequential games with aggregate uncertainty," Journal of Mathematical Economics, 21, 543-562.

- (2008): "Industry Dynamics with Stochastic Demand," Rand Journal of Economics, $39,41-68$. 
Bodoh-Creed, A. (2012): "Approximation of Large Dynamic Games," mimeo - Cornell University.

Caballero, R. J. and M. L. Hammour (1994): "The Cleansing Effect of Recessions," American Economic Review, 84, 1350-68.

_ (1996): "On the Timing and Efficiency of Creative Destruction," The Quarterly Journal of Economics, 111, 805-52.

Davis, S. J. And J. Haltiwanger (1992): "Gross Job Creation, Gross Job Destruction and Employment Reallocation," Quarterly Journal of Economics, 107, 819-863.

Diamond, P. A. (1981): "Mobility Costs, Frictional Unemployment, and Efficiency," Journal of Political Economy, 89, 798-812.

_ (1982a): "Aggregate Demand Management in Search Equilibrium," Journal of Political Economy, 90, 881-94.

- (1982b): "Wage Determination and Efficiency in Search Equilibrium," Review of Economic Studies, 49, 217-27.

Dow, J. And L. Dicks-Mireaux (1958): "The Excess Demand for Labour: A Study of Conditions in Great Britain, 1946-1956," Oxford Economic Papers, 10, 133.

FArber, H. S. (1999): "Mobility and stability: The dynamics of job change in labor markets," in Handbook of Labor Economics, ed. by O. Ashenfelter and D. Card, Elsevier, vol. 3 of Handbook of Labor Economics, chap. 37, 2439-2483.

Furlanetto, F. and N. Groshenny (2012): "Matching Efficiencies and Business Cycle Fluctuations," Working Paper 07, Norges Bank.

Gali, J. And J. Hammour (1992): "Long Run Effects of Business Cycles," Papers 92-26, Columbia - Graduate School of Business.

Hildenbrand, W. (1974): Core and Equilibria of a Large Economy, Princeton University Press.

Jaimovich, N. and H. E. Siu (2012): "The Trend is the Cycle: Job Polarization and Jobless Recoveries," Mimeo, Duke University.

Jovanovic, B. (1987): "Work, Rest, and Search: Unemployment, Turnover, and the Cycle," Journal of Labor Economics, 5, pp. 131-.

Michaillat, P. (2012): "Do Matching Frictions Explain Unemployment? Not in Bad Times," American Economic Review, 102, 1721-50. 
Mortensen, D. T. (1982a): "The Matching Process as a Noncooperative Bargaining Game," in The Economics of Information and Uncertainty, NBER Chapters, 233-258.

(1982b): "Property Rights and Efficiency in Mating, Racing, and Related Games," American Economic Review, 72, 968-79.

Mortensen, D. T. And C. A. Pissarides (1999): "New developments in models of search in the labor market," in Handbook of Labor Economics, Elsevier, vol. 3, chap. 39, $2567-2627$.

Pissarides, C. A. (1984): "Efficient Job Rejection," Economic Journal, 94, 97-108.

(1985): "Short-run Equilibrium Dynamics of Unemployment Vacancies, and Real Wages," American Economic Review, 75, 676-90.

(2000): Equilibrium Unemployment Theory, 2nd Edition, vol. 1 of MIT Press Books, The MIT Press.

Schmeider, J. F., T. von Wachter, And S. Bender (2012): "The Effects of Extended Unemployment Insurance Over the Business Cycle: Evidence from Regression Discontinuity Estimates over Twenty Years," Quarterly Journal of Economics, pp. -.

Shumpeter, J. A. (1939): Business Cycles: A Theoretical, Historitcal, and Statistical Analysis of the Capitalist Process, New York, McGraw-Hill.

Stokey, N. L. And R. E. LuCas (1989): Recursive Methods in Economic Dynamics, Harvard University Press.

\section{Appendix}

\subsection{Proofs of Propositions and Omitted Algebra}

\section{Value Functions Derivation:}

We compute the expected discounted profits beginning from a period with an open vacancy for the richer model described in Section 2.2.2, where possible matches arrive with probability $\alpha \in(q, 1]$. With $\alpha=1$ this corresponds to the simpler model from Section 2.1.

Starting with the case when strategy $\sigma_{g}$ is adopted we have

$$
V\left(\sigma_{g}\right)=\alpha v\left(\sum_{\tau=0}^{\infty} q(1-q)^{\tau}\left(\sum_{s=0}^{\tau} \delta^{s} E_{d}\left(\pi_{d G}\right)+\delta^{\tau+1} V\left(\sigma_{g}\right)\right)\right)+(1-\alpha v) \delta V\left(\sigma_{g}\right),
$$

or

$$
V\left(\sigma_{g}\right)\left(1-\delta\left(1-\alpha v+\frac{q \alpha v}{1-\delta(1-q)}\right)\right)=\frac{\alpha v E_{d}\left(\pi_{d G}\right)}{1-\delta(1-q)}
$$


which simplifies to

$$
V\left(\sigma_{g}\right)(1-\delta(1-q)+\delta \alpha v(1-q))=\alpha v E_{d}\left(\pi_{d G}\right)
$$

or

$$
V\left(\sigma_{g}\right)(1-\delta)(1-\delta(1-q)(1-\alpha v))=\alpha v E_{d}\left(\pi_{d G}\right),
$$

yielding the expression in (4).

When strategy $\sigma_{H b}$ is adopted the value function is instead

$$
\begin{aligned}
& V\left(\sigma_{H b}\right)=\alpha v\left(\sum_{\tau=0}^{\infty} q(1-q)^{\tau}\left(\sum_{s=0}^{\tau} \delta^{s} E_{d}\left(\pi_{d G}\right)+\delta^{\tau+1} V\left(\sigma_{H b}\right)\right)\right) \\
& +\alpha(1-v) p\left(\sum_{\tau=0}^{\infty} q(1-q)^{\tau}\left(\pi_{H B}+\sum_{s=1}^{\tau} \delta^{s} E_{d}\left(\pi_{d G}\right)+\delta^{\tau+1} V\left(\sigma_{H b}\right)\right)\right) \\
& +(1-\alpha(v+p(1-v))) \delta V\left(\sigma_{H b}\right)
\end{aligned}
$$

or

$$
\begin{aligned}
& V\left(\sigma_{H b}\right)\left(1-\delta\left(1-\alpha(v+p(1-v))+\frac{q \alpha(v+p(1-v))}{1-\delta(1-q)}\right)\right) \\
& =\frac{\alpha v E_{d}\left(\pi_{d G}\right)+\alpha p(1-v) E_{d}\left(\pi_{d B}\right)}{1-\delta(1-q)}+\alpha p(1-v)\left(\pi_{H B}-E_{d}\left(\pi_{d B}\right)\right),
\end{aligned}
$$

which simplifies to

$$
\begin{aligned}
& V\left(\sigma_{H b}\right)(1-\delta)(1-\delta(1-q)(1-\alpha(v+p(1-v)))) \\
& =\alpha v E_{d}\left(\pi_{d G}\right)+\alpha p(1-v)\left(E_{d}\left(\pi_{d B}\right)+(1-\delta(1-q))\left(\pi_{H B}-E_{d}\left(\pi_{d B}\right)\right)\right),
\end{aligned}
$$

yielding the expression in (5).

Finally, for the strategy of hiring good and bad workers in either demand state, $\sigma_{a}$, interesting only if $\alpha<<1$, we have

$$
V\left(\sigma_{a}\right)=\alpha\left(\sum_{\tau=0}^{\infty} q(1-q)^{\tau}\left(\sum_{s=0}^{\tau} \delta^{s} E_{d b}\left(\pi_{d b}\right)+\delta^{\tau+1} V\left(\sigma_{a}\right)\right)\right)+(1-\alpha) \delta V\left(\sigma_{a}\right),
$$

or

$$
V\left(\sigma_{a}\right)\left(1-\delta\left(1-\frac{\alpha(1-\delta)(1-q)}{1-\delta(1-q)}\right)\right)=\frac{\alpha E_{d b}\left(\pi_{d b}\right)}{1-\delta(1-q)},
$$

which simplifies to

$$
V\left(\sigma_{a}\right)(1-\delta)(1-\delta(1-q)(1-\alpha))=\alpha E_{d b}\left(\pi_{d b}\right)
$$

yielding the expression in 6 .

Proof of Proposition 1: 
Consider the expression for $V\left(\sigma_{g}\right)$ and $V\left(\sigma_{H b}\right)$ from (1) and (2), respectively. Both denominators are positive, so that $V\left(\sigma_{g}\right) \leq V\left(\sigma_{H b}\right)$ if and only if

$$
\begin{aligned}
& v E_{d}\left(\pi_{d G}\right)(1-\delta(1-q)(1-v-p(1-v))) \leq \\
& \left(v E_{d}\left(\pi_{d G}\right)+p(1-v)\left(\delta(1-q) E_{d}\left(\pi_{d B}\right)+(1-\delta(1-q)) \pi_{H B}\right)\right)(1-\delta(1-q)(1-v))
\end{aligned}
$$

or

$$
\begin{aligned}
& v E_{d}\left(\pi_{d G}\right) \delta(1-q) p(1-v) \leq \\
& \left(p(1-v)\left(\delta(1-q) E_{d}\left(\pi_{d B}\right)+(1-\delta(1-q)) \pi_{H B}\right)\right)(1-\delta(1-q)(1-v))
\end{aligned}
$$

and dividing both sides by $p(1-v)$ this condition becomes

$$
v E_{d}\left(\pi_{d G}\right) \delta(1-q) \leq\left(\delta(1-q) E_{d}\left(\pi_{d B}\right)+(1-\delta(1-q)) \pi_{H B}\right)(1-\delta(1-q)(1-v))
$$

or

$$
\frac{v E_{d}\left(\pi_{d G}\right)}{(1-\delta(1-q)(1-v))} \leq \frac{\pi_{H B}}{\delta(1-q)}-\left(\pi_{H B}-E_{d}\left(\pi_{d B}\right)\right)
$$

which corresponds to $(3)$.

\section{Proof of Proposition 2;}

Let $m_{t}=U$ denote a situation where no worker is employed by the firm at the end of period $t$.

When $V\left(\sigma_{H b}\right)>V\left(\sigma_{g}\right)$, the transition matrix of the Markov process describing the evolution of $m_{t}$ along periods with back-to-back $H$ demand state is

$$
\mathbf{T}_{H H}=\left[\begin{array}{ccc}
(1-q)+q v & q(1-v) & 0 \\
q v & (1-q)+q(1-v) & 0 \\
v & (1-v) & 0
\end{array}\right]
$$

where the first row corresponds to the state $m=G$, the second row to $m=B$, and the third row to $m=U$.

The $\tau$-fold matrix product of this matrix, $\left(\mathbf{T}_{H H} \times \mathbf{T}_{H H} \times \ldots \times \mathbf{T}_{H H}\right) \tau$ times, is denoted 
$\left(\mathbf{T}_{H H}\right)^{\tau}$. This matrix is ${ }^{23}$

$$
\begin{aligned}
\left(\mathbf{T}_{H H}\right)^{\tau} & =\left[\begin{array}{ccc}
\frac{1}{v}(v-1) & 0 & 1 \\
1 & 0 & 1 \\
0 & 1 & 1
\end{array}\right]\left[\begin{array}{ccc}
(1-q)^{\tau} & 0 & 0 \\
0 & 0 & 0 \\
0 & 0 & 1
\end{array}\right]\left[\begin{array}{ccc}
-v & v & 0 \\
-v & v-1 & 1 \\
v & 1-v & 0
\end{array}\right] \\
& =\left[\begin{array}{ccc}
v+(1-q)^{\tau}(1-v) & 1-v-(1-q)^{\tau}(1-v) & 0 \\
v-v(1-q)^{\tau} & 1-v+v(1-q)^{\tau} & 0 \\
v & 1-v & 0
\end{array}\right],
\end{aligned}
$$

from which it is immediate to see that the probability of transitioning from $m_{t-\tau}=G$ to $m_{t}=B$ is $(1-v)\left(1-(1-q)^{\tau}\right)$, strictly increasing in $\tau$.

\section{Proof of Proposition 3;}

We measure the aggregate states of employment at the end of each period and consider the richer model with random arrival of possible matches at rate $\alpha$ (this covers the $\alpha=1$ case).

The transition from $g_{t}, b_{t}$ to $g_{t+1}, b_{t+1}$ when demand is $H$ is as follows:

$$
\begin{aligned}
g_{t+1} & =\underbrace{(1-q) g_{t}}_{\text {old good matches }}+\underbrace{v \alpha\left(q\left(b_{t}+g_{t}\right)+u_{t}\right)}_{\text {new good matches }} \\
b_{t+1} & =\underbrace{(1-q) b_{t}}_{\text {old bad matches }}+\underbrace{(1-v) \alpha\left(q\left(b_{t}+g_{t}\right)+u_{t}\right)}_{\text {new bad matches }} \\
u_{t+1} & =1-g_{t+1}-b_{t+1}=(1-\alpha)\left(q\left(b_{t}+g_{t}\right)+u_{t}\right) .
\end{aligned}
$$

The system of difference equations (7), (8), and (9) admits a unique globally stable steady state:

$$
\begin{aligned}
g^{S S} & =\frac{\alpha v}{1-(1-\alpha)(1-q)}, \\
b^{S S} & =\frac{\alpha(1-v)}{1-(1-\alpha)(1-q)}, \\
u^{S S} & =\frac{(1-\alpha) q}{1-(1-\alpha)(1-q)} .
\end{aligned}
$$

(a) With $d=H$ the economy tends toward full employment $\left(b^{S S}+g^{S S}=\frac{\alpha}{1-(1-\alpha)(1-q)}\right.$, or $b^{S S}+g^{S S}=1$ when $\left.\alpha=1\right)$. This is the maximum level that can be reached and will never be crossed. Therefore $b_{t}+g_{t}$ is (weakly) increasing along sequences of high demand states.

${ }^{23}$ The spectral decomposition of $\mathbf{T}_{H H}$ is:

$$
\left[\begin{array}{ccc}
\frac{1}{v}(v-1) & 0 & 1 \\
1 & 0 & 1 \\
0 & 1 & 1
\end{array}\right]\left[\begin{array}{ccc}
1-q & 0 & 0 \\
0 & 0 & 0 \\
0 & 0 & 1
\end{array}\right]\left[\begin{array}{ccc}
-v & v & 0 \\
-v & v-1 & 1 \\
v & 1-v & 0
\end{array}\right]
$$

To compute the $\tau$-fold matrix product we simply need to take the $\tau^{\text {th }}$ power of the eigenvalues in the characteristic matrix. 
(b) Clearly since $b_{0}<b_{S S}, b_{t}<b_{S S}$ will always be the case $\left(b_{t}\right.$ approaches $b_{S S}$ from below, then drops during periods of low-demand, etc.). Therefore $b_{t}$ is increasing along periods of back-to-back high-demand.

From 10 and 11 we have $\frac{b^{S S}}{b^{S S}+g^{S S}}=(1-v)$. Since we assume that $\frac{b_{t}}{g_{t}}<\frac{1-v}{v}$ (or equivalently $\frac{b_{t}}{b_{t}+g_{t}}<1-v$ ) when the sequence of high-demand periods started, this ratio is growing along the sequence, approaching the steady state from below.

(c) The number of firms that would fail if the next period has $d_{t+1}=L$ is

$$
b_{t} \phi\left(\frac{b_{t}}{b_{t}+g_{t}}\right),
$$

this number increases since in (b) we showed that both $b_{t}$ and $\frac{b_{t}}{b_{t}+g_{t}}$ increase and $\phi$ is an increasing function.

Analogously, the fraction of firms that will fail if demand transitions to low in the next period is

$$
\frac{b_{t}}{b_{t}+g_{t}} \phi\left(\frac{b_{t}}{b_{t}+g_{t}}\right)
$$

also increasing for the same reasoning as in (c).

\section{Proof of Proposition 4:}

The transition from $g_{t}, b_{t}$ to $L, g_{t+1}, b_{t+1}$ is described by the following system:

$$
\begin{aligned}
g_{t+1} & =\underbrace{(1-q) g_{t}}_{\text {old good matches }}+\underbrace{v \alpha\left(q\left(b_{t}\left(1-\phi\left(\frac{b_{t}}{b_{t}+g_{t}}\right)\right)+g_{t}\right)+u_{t}\right)}_{\text {new good matches }} \\
b_{t+1} & =\underbrace{(1-q) b_{t}\left(1-\phi\left(\frac{b_{t}}{b_{t}+g_{t}}\right)\right)}_{\text {old bad matches in non-failed firms }} \\
u_{t+1} & =\underbrace{b_{t} \phi\left(\frac{b_{t}}{b_{t}+g_{t}}\right)}_{\text {workers from failed firms }}+\underbrace{(1-v \alpha)\left(q\left(b_{t}\left(1-\phi\left(\frac{b_{t}}{b_{t}+g_{t}}\right)\right)+g_{t}\right)+u_{t}\right)}_{\text {unmatched workers }} .
\end{aligned}
$$

(d) From (15) it is trivial to see that $b_{t}$ is decreasing throughout the recession. To see that

$$
\frac{b_{t+1}}{b_{t+1}+g_{t+1}}<\frac{b_{t}}{b_{t}+g_{t}}
$$

note that $g_{t}$ is increasing because as long as $g_{0}$ is assumed to be below its maximal steady state level (which is the limit toward which $g$ asymptotes when $d=L$ forever) this must be the case. But then with $b_{t+1}<b_{t}$ and $g_{t+1}>g_{t}$ (17) must hold. Recalling that the number of firms that fail in each period is

$$
b_{t} \phi\left(\frac{b_{t}}{b_{t}+g_{t}}\right)
$$


all the above implies that this number is decreasing along the sequence of low demand states. For the fraction of failing firms, as in (13), the same reasoning applies.

The above reasoning also implies (e).

\section{Proof of Proposition 5 ;}

Note that $M_{t}^{\sigma^{*}}\left(u_{0}, \mu_{0}, \mathbf{d}\right)$ is defined recursively using the one-period transition function $\mathbf{T}^{\sigma^{*}}:$

$$
\begin{aligned}
M_{1}^{\sigma^{*}}\left(u_{0}, \mu_{0}, d_{1}\right) & =\mathbf{T}^{\sigma^{*}}\left(u_{0}, \mu_{0}, d_{1}\right), \text { and } \\
M_{t}^{\sigma^{*}}\left(u_{0}, \mu_{0}, \mathbf{d}\right) & =\mathbf{T}^{\sigma^{*}}\left(M_{t-1}^{\sigma^{*}}\left(u_{0}, \mu_{0},\left(d_{1}, \ldots, d_{t-1}\right)\right), d_{t}\right) .
\end{aligned}
$$

Monotonicity of $\sigma^{*}$ and $\phi$ in $d$ imply that $M_{1}^{\sigma^{*}}\left(u_{0}, \mu_{0}, d_{1}^{\prime}\right)$ dominates $M_{1}^{\sigma^{*}}\left(u_{0}, \mu_{0}, d_{1}\right)$, since a higher demand state induces less layoffs and worse hiring, thus implying $u_{1}<u_{1}^{\prime}$ and $\mu_{1}$ to be first order stochastically dominated by $\mu_{1}^{\prime}$.

By the same reasoning, if $M_{t-1}^{\sigma^{*}}\left(u_{0}, \mu_{0},\left(d_{1}^{\prime}, \ldots, d_{t-1}^{\prime}\right)\right)$ dominates $M_{t-1}^{\sigma^{*}}\left(u_{0}, \mu_{0},\left(d_{1}, \ldots, d_{t-1}\right)\right)$, no reversals and monotonicity of $\sigma^{*}$ and $\phi$ imply that $M_{t}^{\sigma^{*}}\left(u_{0}, \mu_{0}, \mathbf{d}^{\prime}\right)$ dominates $M_{t}^{\sigma^{*}}\left(u_{1}, \mu_{1}, \mathbf{d}\right)$. By induction the statement holds.

\section{Proof of Corollary 2:}

Since $\phi$ is non-increasing in $\mu_{t}$ (in the first order stochastic dominance sense) and $m$, and $\mu_{t}^{\prime}$ dominates $\mu_{t}$, we have the following chain of inequalities:

$$
\int_{M} \phi\left(\mu_{t}^{\prime}, d_{t+1}, m\right) d \mu_{t}^{\prime}(m) \leq \int \phi\left(\mu_{t}, d_{t+1}, m\right) d \mu_{t}^{\prime}(m)<\int \phi\left(\mu_{t}, d_{t+1}, m\right) d \mu_{t}(m),
$$

where the first quantity on the left is the fraction of firms going bankrupt after $\left(\mathbf{d}^{\prime}, d_{t+1}\right)$ with starting employment state $u_{1}, \mu_{1}$, while the last on the right is the same quantity following $\left(\mathbf{d}, d_{t+1}\right)$ with the same initial state.

\section{Proof of Proposition 6;}

From the inductive construction of $M_{t}^{\sigma^{*}}$ in the proof of Proposition 5 it follows that for any sequence of demand states and for all $t, d_{t} \geq d_{t-1}$ implies that $M_{t-1}^{\sigma^{*}}\left(u_{0}, \mu_{0},\left(d_{1}, \ldots, d_{t-1}\right)\right)$ dominates $M_{t}^{\sigma^{*}}\left(u_{0}, \mu_{0},\left(d_{1}, \ldots, d_{t}\right)\right)=\mathbf{T}^{\sigma^{*}}\left(M_{t-1}^{\sigma^{*}}\left(u_{0}, \mu_{0},\left(d_{1}, \ldots, d_{t-1}\right)\right), d_{t}\right)$. This again follows applying no reversal and monotonicity of $\sigma^{*}$ and $\phi$ iteratively. Then

$$
E M_{t}^{\sigma^{*}}\left(u_{0}, \mu_{0}, d_{1}\right)=E\left[M_{t}^{\sigma^{*}}\left(u_{0}, \mu_{0}, \mathbf{d}\right) \mid \mathbf{d} \in G_{t}\left(d_{1}\right)\right]
$$

is dominated by

$$
E\left[M_{t-1}^{\sigma^{*}}\left(u_{0}, \mu_{0},\left(d_{1}, \ldots, d_{t-1}\right)\right) \mid \mathbf{d} \in G_{t}\left(d_{1}\right)\right]=E\left[M_{t-1}^{\sigma^{*}}\left(u_{0}, \mu_{0}, \mathbf{d}^{\prime}\right) \mid \mathbf{d}^{\prime} \in G_{t-1}\left(d_{1}\right)\right]
$$

which is equal to $E M_{t-1}^{\sigma^{*}}\left(u_{0}, \mu_{0}, d_{1}\right)$. 


\subsection{Equilibrium Existence}

We show the existence of an equilibrium $\sigma^{*}$ that is continuous in both arguments $\mu$ and $d$. The proof consists of showing the following claims:

- When a continuous strategy $\hat{\sigma}$ is adopted by all firms, the Markov transition $\mathbf{T}^{\hat{\sigma}}$ describing the evolution of $(\mu, d)$ is continuous.

- The optimal solution of the dynamic programming problem of the firm, taking $\mathbf{T}^{\hat{\sigma}}$ as given, results in a continuous function $\sigma$.

- For any given initial state, the sum of expected future discounted profits as a function of own strategy $\sigma$ and others' strategy $\hat{\sigma}$ is continuous in the domain of continuous strategies.

- The best reply function in the firm's problem is continuous in the domain of continuous strategies, and admits a fixed point $\sigma^{*}$, constituting an equilibrium.

LEMMA 1 If the strategy $\hat{\sigma}$ adopted by all firms is a continuous function, the solution to the dynamic programming problem of the single firm taking $\hat{\sigma}$ as given is a continuous function $\sigma$.

\section{Proof of Lemma 1:}

The state variable of the firm is a tuple $s=(u, \mu, d, e, b, m)$, where $(u, \mu, d)$ evolves according to the transition $\mathbf{T}^{\hat{\sigma}}, e \in\{0,1\}$ denotes whether or not the firm has an open vacancy $(e=0), b \in\{0,1\}$ indicates whether or not bankruptcy occurred $(b=1)$, and $m$ is the worker employed by the firm (when $e=0$ or $b=1 \mathrm{~m}$ can be picked arbitrarily without any loss of generality). Let $S=[0,1] \times \mathcal{P}(M) \times D \times\{0,1\}^{2} \times M$ be the state space of the Markovian decision problem faced by the firm.

With an action $a$ being the probability of hiring, the feasible action set is simply $\mathcal{A}(s)=$ $[0,1]$ if $s$ is such that $e=b=0$ (there is an open vacancy and the firm didn't fail), otherwise no hiring decision has to be made so that $\mathcal{A}(s)=\{0\}$.

Let $\mathbf{P}^{\hat{\sigma}}: S \times[0,1] \rightarrow \mathcal{P}(S)$ be the transition mapping state $s$ and action $a$ into the probability measure $\mathbf{P}^{\hat{\sigma}}(s, a)$ over $S$.

First we argue that the following is true:

Claim 1 If $\hat{\sigma}$ is continuous, the transition $\mathbf{T}^{\hat{\sigma}}: \mathcal{P}(M) \times D \rightarrow \mathcal{P}(M) \times \mathcal{P}(D)$ is continuous. Thus $\mathbf{P}^{\hat{\sigma}}(s, a)$ is continuous.

Proof. To see this, notice that $\mathbf{T}^{\hat{\sigma}}(u, \mu, d)$ is the product of a deterministic component mapping $(u, \mu, d)$ into the new employment state $u^{\prime}, \mu^{\prime}$, and an iid random component drawing $d^{\prime}$ in the next period according to the distribution $\eta$ : abusing notation $\mathbf{T}^{\hat{\sigma}}(u, \mu, d)=\left(u^{\prime}, \mu^{\prime}, \eta\right)$ 
for all $(u, \mu, d)$. Letting $\mathbf{T}_{1}^{\hat{\sigma}}(u, \mu, d)=\left(u^{\prime}, \mu^{\prime}\right)$, this is the function whose continuity is necessary and sufficient for the continuity of $\mathbf{T}^{\hat{\sigma}}$. $\mathbf{T}_{1}^{\hat{\sigma}}(u, \mu, d)$ depends on $\phi$ and $q$ for layoffs and exogenous quitting, and on $\hat{\sigma}$ (and $F$ ) for hiring. With $\phi$ and $\hat{\sigma}$ continuous by assumption and $F$ non-atomic this is a composition of continuous functions, preserving continuity. With $\mathbf{T}^{\hat{\sigma}}$ continuous, continuity of the full transition $\mathbf{P}^{\hat{\sigma}}$ follows since the transition of $e$ is iid according to the quitting rate $q$ (or degenerate when $e=0$ ), the transition to bankruptcy (probability that $b=1$ in the next period) when $e=1$ (and $b=0)$ is $\int_{D} \phi\left(\mathbf{T}_{1}^{\hat{\sigma}}(\mu, d), d^{\prime}, m\right) \mathrm{d} \eta\left(d^{\prime}\right)$ - continuous from what we have just shown, and the transition of $m$ is continuous in the action $a$ since $F$ is non-atomic. This proves the claim.

We now consider the dynamic programming problem of the firm, with Bellman equation

$$
V(s)=\max _{a \in \mathcal{A}(s)} \tilde{\pi}(s, a)+\delta \int_{S} V\left(s^{\prime}\right) d \mathbf{P}^{\hat{\sigma}}(s, a),
$$

and the policy function $\sigma(s)$ being the solution to the maximization problem on the righthand side in (18). Uniqueness of this solution for all $s$ follows from the fact that the hiring cutoff is always unique as discussed in Section 3.2.

The problem in (18) satisfies the conditions in Theorem 9.6 in Stokey and Lucas (1989), and continuity of $\sigma$ follows.

From Lemma 1 we can focus on continuous strategies only, denoting the set of continuous strategies mapping $S$ in $[0,1]$ by $\hat{\Sigma}$.

Now, denote with $\Pi(s ; \sigma, \hat{\sigma})$ the discounted expected profits from any initial state $s$ of a firm adopting strategy $\sigma$, while the remaining firms in the economy adopt strategy $\hat{\sigma}$.

LEMma 2 The function $\Pi(s ; \cdot, \cdot): \hat{\Sigma} \times \hat{\Sigma} \rightarrow \mathbb{R}$ is continuous for all $s \in S$.

\section{Proof of Lemma 2;}

Letting $\Pi^{T}(s ; \sigma, \hat{\sigma})$ be the expected profits of the $T<\infty$ periods version of the model, for any $\varepsilon>0$ and for any initial state $s$ there exists a large enough $T$ such that $\left|\Pi(s ; \sigma, \hat{\sigma})-\Pi^{T}(s ; \sigma, \hat{\sigma})\right|<$ $\frac{\varepsilon}{2}$ (profits are bounded and $\delta<1$ ). The result can then be proven by showing that for all $T$ $\Pi^{T}(s ; \cdot, \cdot)$ is a continuous function.

Proceeding by induction, for $T=1 \Pi^{T}(s ; \sigma, \hat{\sigma})=\tilde{\pi}(s, \sigma(s))$ for all $s$. This function is continuous since $\sigma \in \hat{\Sigma}$ and $\tilde{\pi}$ is continuous.

Assuming that for all $t<T$, and all $s \in S, \Pi^{t}(s, \cdot, \cdot)$ is continuous, then

$$
\Pi^{T}(s, \sigma, \hat{\sigma})=\Pi^{T-1}(s, \sigma, \hat{\sigma})+\delta \int_{S} \tilde{\pi}\left(s^{\prime}, \sigma\left(s^{\prime}\right)\right) d \mathbf{W}^{T}(s, \sigma, \hat{\sigma}),
$$

where $\mathbf{W}^{T}: S \times \hat{\Sigma}^{2} \rightarrow \mathcal{P}(S)$ is the $T$-periods transition from $S$ to $\mathcal{P}(S)$ when the firm's strategy is $\sigma$ and the other firms' strategy is $\hat{\sigma}$. Formally: $\mathbf{W}^{1}(s, \sigma, \hat{\sigma})=\mathbf{P}^{\hat{\sigma}}(s, \sigma(s))$, and recursively $\mathbf{W}^{T}(s, \sigma, \hat{\sigma})=\int_{S} \mathbf{P}^{\hat{\sigma}}\left(s^{\prime}, \sigma\left(s^{\prime}\right)\right) d \mathbf{W}^{T-1}(s, \sigma, \hat{\sigma})$. Continuity of $\mathbf{P}^{\hat{\sigma}}(\cdot, \cdot)$ was shown in Claim 1, and non-atomicity of $F$ and continuity of $\phi$ ensure that also $\mathbf{P}(s, a)$ (seen as a 
function of $\hat{\sigma}$ ) is continuous. Therefore the $T$-periods transition $\mathbf{W}^{T}$ is continuous implying the continuity of $\Pi^{T}(s, \cdot, \cdot)$ for all $T$ and all $s$.

From Lemma 1 and 2 we know that, for any $s$, the objective of the maximization problem faced by the firm,

$$
\max _{\sigma \in \hat{\Sigma}} \Pi(s ; \sigma, \hat{\sigma}),
$$

is continuous in $\sigma$ and $\hat{\sigma}$, and the solution is always a singleton. By Berge's theorem of the maximum the best reply function $B R: \hat{\Sigma} \rightarrow \hat{\Sigma}$ defined as

$$
B R(\hat{\sigma})=\arg \max _{\sigma \in \hat{\Sigma}} \Pi(s ; \sigma, \hat{\sigma})
$$

is continuous. Since $\hat{\Sigma}$ is compact and convex, Brouwer's fixed point theorem applies and an equilibrium strategy $\sigma^{*}$ satisfying $\sigma^{*}=B R\left(\sigma^{*}\right)$ must exist. I 


\subsection{Empirical Appendix}

In this appendix we conduct additional analyses of our data regarding the relationship between an expansion's duration and the employment drop at crisis onset. In particular, we check that the negative relationship is robust to alternative specifications and definitions.

Recall that our main specification in Section 4 was as follows. Letting

- $e_{i, j}=$ job growth at crisis $i$ onset (in area $j$ ),

- $M e_{i, j}=$ average job growth in area $j$ during the expansion preceding crisis $i$,

- $M p_{i, j}=$ average income growth in area $j$ during the expansion preceding crisis $i$,

- $\operatorname{pop}_{i, j}=$ population growth at crisis $i$ onset (in area $j$ ),

we estimated

$e_{i, j}=\alpha+\beta_{1}$ Exp. Duration $+\beta_{2} M p_{i, j}+\beta_{3} M e_{i, j}+\beta_{4}$ pop $_{i, j}+\delta_{\text {State }_{j}}+\mu_{Y e a r_{i}}+\epsilon_{i, j}$.

Now, rather than looking at jobs and income growth, we look at deviations from expansion averages. Specifically, let

- $\Delta e_{i, j}=e_{i, j}-M e_{i, j}$

- $\Delta p_{i, j}=$ income growth at crisis $i$ onset (in area $j$ ) minus its expansion average, and

- $\operatorname{pop}_{i, j}=$ population growth at crisis $i$ onset (in area $j$ ).

We estimate the following:

$$
\Delta e_{i, j}=\alpha+\beta_{1} \text { Expansion Duration }+\beta_{2} \Delta p_{i, j}+\beta_{3} \text { pop }_{i, j}+\delta_{\text {State }_{j}}+\mu_{Y_{\text {ear }}}+\epsilon_{i, j}
$$

The OLS regression results are reported in Table 2, with the relationship between the deviation of job growth and the expansion's duration being negative and significant in all of the specifications. With coefficient estimates between -0.08 and -0.12 , this linear model implies that 5 additional years of expansions correspond to an additional drop in job growth (from its average expansion level) of between 0.40 and 0.60 percentage points.

Because in our data, the great recession of 2008-2009 impacted almost every area and had an extraordinary impact on employment across the whole US, in columns 3-6 we report the same regressions run on a restricted sample focusing only on the 1969-2007 period.

We can also look at this graphically, in the spirit of the histogram reported in Figure 1 in the introduction. Figure 3 , reports the Kernel CDFs of $\Delta e_{i, j}$ for three groups of expansion's duration. These display a clear ordering in the first-order stochastic dominance sense, consistent with our theoretical results in Section 3. When testing the null hypothesis that any two of these CDFs do not differ, a Kolmogorov-Smirnoff test rejects the null at any of the usual significance levels. 
Table 2: OLS regression. Robust standard errors, clustered at the area level.

\begin{tabular}{|c|c|c|c|c|c|c|}
\hline \multirow[b]{2}{*}{ Duration of Expansion } & \multicolumn{6}{|c|}{ Job Growth (onset of crisis) minus expansion avg. } \\
\hline & $\begin{array}{c}-0.080^{* * *} \\
0.0205\end{array}$ & $\begin{array}{c}-0.088^{\star * \star} \\
0.0185\end{array}$ & $\begin{array}{c}-0.075^{\star \star \star} \\
0.0194\end{array}$ & $\begin{array}{c}-0.085^{\star * \star} \\
0.0214\end{array}$ & $\begin{array}{c}-0.091^{* * *} \\
0.0189\end{array}$ & $\begin{array}{c}-0.117^{\star * *} \\
0.0199\end{array}$ \\
\hline $\begin{array}{l}\text { Propietors' Income } \\
\text { Growth (onset of } \\
\text { crisis) minus } \\
\text { expansion avg. }\end{array}$ & $\begin{array}{c}0.003^{\star \star *} \\
0.0008\end{array}$ & $\begin{array}{l}0.002^{\star *} \\
0.0010\end{array}$ & $\begin{array}{c}0.003^{\star \star *} \\
0.0007\end{array}$ & $\begin{array}{c}0.003^{\star * *} \\
0.0009\end{array}$ & $\begin{array}{c}0.002^{* *} \\
0.0010\end{array}$ & $\begin{array}{c}0.004^{\star * *} \\
0.0006\end{array}$ \\
\hline $\begin{array}{l}\text { Population Growth } \\
\text { (onset of crisis) }\end{array}$ & $\begin{array}{l}-0.128 \\
0.0962\end{array}$ & $\begin{array}{l}-0.087 \\
0.0694\end{array}$ & $\begin{array}{c}-0.157^{\star} \\
0.0924\end{array}$ & $\begin{array}{l}-0.119 \\
0.0933\end{array}$ & $\begin{array}{l}-0.060 \\
0.0681\end{array}$ & $\begin{array}{c}-0.094 \\
0.0884\end{array}$ \\
\hline Constant & $\begin{array}{c}1.296^{* * *} \\
0.2326\end{array}$ & $\begin{array}{c}0.956^{* * *} \\
0.1041\end{array}$ & $\begin{array}{c}-0.364^{* * *} \\
0.1045\end{array}$ & $\begin{array}{c}1.262^{* * *} \\
0.2364\end{array}$ & $\begin{array}{c}2.618^{* * *} \\
0.0688\end{array}$ & $\begin{array}{l}-0.021 \\
0.1017\end{array}$ \\
\hline Obs. & 1273 & 1273 & 1273 & 1163 & 1163 & 1163 \\
\hline FE & State, Year & Year & $\mathrm{X}$ & State, Year & Year & $\mathrm{X}$ \\
\hline Years & $1969-2011$ & $1969-2011$ & $1969-2011$ & $1969-2007$ & $1969-2007$ & $1969-2007$ \\
\hline R-squared & 0.496 & 0.451 & 0.024 & 0.439 & 0.383 & 0.040 \\
\hline
\end{tabular}

\subsubsection{VAR analysis}

To verify that our findings do not depend on the chosen specifications, and in particular on the simple way we control for trends by using expansion averages, in this section we conduct an alternative test for the negative correlation between job growth and expansion duration at the onset of crises in the BEA areas.

For each of the 179 areas, using the observed 42 years of proprietors' income and number of wage and salary jobs, we estimate the following 2-lag vector autoregression model (VAR): ${ }^{24}$

$$
\begin{gathered}
E m p_{j, t}=\alpha_{j}^{E}+\beta_{j}^{E, 1} E m p_{j, t-1}+\beta_{j}^{I, 1} I n c_{j, t-1}+\beta_{j}^{E, 2} E m p_{j, t-2}+\beta_{j}^{I, 2} \operatorname{Inc}_{j, t-2}+\varepsilon_{j, t}^{E}, \\
\operatorname{Inc}_{j, t}=\alpha_{j}^{I}+\delta_{j}^{E, 1} E m p_{j, t-1}+\delta_{j}^{I, 1} I n c_{j, t-1}+\delta_{j}^{E, 2} E m p_{j, t-2}+\delta_{j}^{I, 2} I n c_{j, t-2}+\varepsilon_{j, t}^{I},
\end{gathered}
$$

where $E m p_{j, t}$ and $I n c_{j, t}$ denote number of wage and salary jobs and proprietors' income in area $j$, year $t$, respectively.

In each area $j$, from the fitted series of number of jobs, denoted $\widehat{E m p}_{j, 1969}, \ldots, \widehat{E m p}_{j, 2011}$, we compute the corresponding residuals of the jobs series: $\widehat{\varepsilon}_{j, 1969}^{E}, \ldots, \widehat{\varepsilon}_{j, 2011}^{E}$ :

$$
\widehat{\varepsilon}_{j, t}^{E}=E m p_{j, t}-\widehat{E m p}_{j, t} ; \quad t=1969, \ldots, 2011 ; j=1, \ldots, 179 .
$$

For each of the 1273 crises in our data described above, $i=1, \ldots, 1273$, letting $j_{i}$ and $t_{i}$ denote the area and the year of crisis $i$, we then estimate the following equation:

$$
\widehat{\varepsilon}_{j_{i}, t_{i}}^{E}=\alpha+\beta \text { Exp. Duration }{ }_{i}+\mu_{t_{i}}+\nu_{i} ; \quad i=1, \ldots, 1273
$$

\footnotetext{
${ }^{24}$ We use indexed series to be able to compare magnitudes of estimated residuals across different areas in a meaningful way.
} 
Figure 3: Kernel CDFs of $\Delta e_{i, j}$ for various expansion durations.

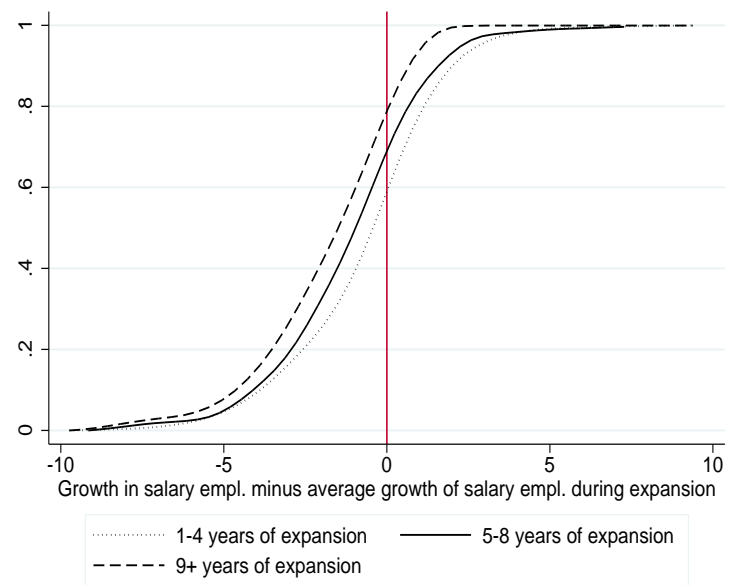

Estimates are reported below in Table 3: we reject the null hypothesis that the duration of the preceding expansion does not affect the deviation in number of jobs at crisis onset $(\beta=0)$ in all specifications.25

Table 3: Equation 21

\begin{tabular}{lcccc}
\hline \multicolumn{4}{c}{ Estimated residual of number of jobs from area-level VAR (onset of crisis) } \\
\hline \multirow{2}{*}{ Duration of Expansion } & $-0.188^{* \star *}$ & $-0.057^{*}$ & $-0.144^{* \star *}$ & $-0.144^{\star * *}$ \\
& 0.0214 & 0.0309 & 0.0262 & 0.0262 \\
\hline \multirow{2}{*}{ Constant } & & $-0.828^{* * *}$ & & 0.149 \\
& & 0.1423 & 1.8149 \\
\hline Obs. & 1273 & 1273 & 1273 & 1273 \\
FE & $X$ & $X$ & Year & Year \\
Years & $1969-2011$ & $1969-2011$ & $1969-2011$ & $1969-2011$ \\
R-squared & 0.057 & 0.003 & 0.511 & 0.469 \\
\hline
\end{tabular}

\subsubsection{Alternative Definitions of Crisis}

In our empirical analysis thus far, we adopted a simple and intuitive definition of the onset of a crisis, identifying this in the data as the first year of negative propietors' income growth following one or more years of positive growth for the same variable. In what follows, we show that the negative relationship between expansion duration and drop in number of jobs at the crisis' onset is robust to alternative definitions of crisis.

\footnotetext{
${ }^{25}$ Estimating the model with year fixed effect controls for year-specific aggregate effects impacting different areas. This is not controlled for within a given area-level VAR, but likely plays an important role in the dynamics of firms' income and number of jobs.
} 


\section{Redefining Crises 1:}

A viable alternative definition of crisis could require the drop in propietors' income to be of a given size (not simply below 0 ), say $-0.1 \%,-0.5 \%$, etc. In Table 4 below we report, for 20 drops between 0 and $2 \%$ used to define a crisis, the estimates of $\beta_{1}$ from equation (19), along with their standard errors and t-statistics, as well as the number of crises and mean duration resulting from this different definitions. In Table 5 we repeat the same analysis using the specification in equation $(20)$ instead.

All our results are robust to these alternative definitions.

Table 4: $\beta_{1}$ estimates for alternative definitions of crisis, equation (19)

\begin{tabular}{cccccc}
\hline $\begin{array}{c}\text { Drop in } \\
\text { propietors' } \\
\begin{array}{c}\text { income defining a } \\
\text { crisis (\%) }\end{array}\end{array}$ & $\begin{array}{c}\text { Average } \\
\text { duration of } \\
\text { expansions }\end{array}$ & $\begin{array}{c}\text { Number of } \\
\text { crises }\end{array}$ & $\begin{array}{c}\text { Coefficient on } \\
\text { duration in } \\
\text { equation 20 }\end{array}$ & $\begin{array}{c}\text { Standard } \\
\text { Error }\end{array}$ & T-statistics \\
\hline 0 & 3.30 & 1268 & -0.039 & 0.0168 & -2.296 \\
0.1 & 3.30 & 1259 & -0.038 & 0.0169 & -2.266 \\
0.2 & 3.29 & 1248 & -0.042 & 0.0167 & -2.535 \\
0.3 & 3.26 & 1231 & -0.041 & 0.0167 & -2.441 \\
0.4 & 3.26 & 1211 & -0.047 & 0.0167 & -2.801 \\
0.5 & 3.25 & 1199 & -0.046 & 0.0169 & -2.739 \\
0.6 & 3.23 & 1190 & -0.048 & 0.0174 & -2.741 \\
0.7 & 3.22 & 1177 & -0.047 & 0.0180 & -2.632 \\
0.8 & 3.21 & 1165 & -0.047 & 0.0181 & -2.589 \\
0.9 & 3.21 & 1155 & -0.047 & 0.0179 & -2.647 \\
1 & 3.21 & 1144 & -0.043 & 0.0177 & -2.443 \\
1.1 & 3.20 & 1135 & -0.042 & 0.0176 & -2.391 \\
1.2 & 3.19 & 1125 & -0.045 & 0.0177 & -2.525 \\
1.3 & 3.19 & 1119 & -0.047 & 0.0178 & -2.635 \\
1.4 & 3.17 & 1101 & -0.050 & 0.0182 & -2.743 \\
1.5 & 3.13 & 1089 & -0.054 & 0.0188 & -2.885 \\
1.6 & 3.13 & 1081 & -0.055 & 0.0188 & -2.893 \\
1.7 & 3.12 & 1067 & -0.056 & 0.0191 & -2.929 \\
1.8 & 3.12 & 1057 & -0.056 & 0.0194 & -2.893 \\
1.9 & 3.11 & 1050 & -0.055 & 0.0194 & -2.833 \\
2 & 3.05 & 1040 & -0.056 & 0.0211 & -2.666 \\
\hline
\end{tabular}

Note: Expansion as long as propietors' income growth $>0$

\section{Redefining Crises 2:}

Another alternative way of defining an area-level crisis is to look at episodes in which, in year $t-1$ proprietors' income growth was positive, say $x_{t-1}>0$, and in year $t$ proprietors' income growth $x_{t}$ drops by, say, $1 \%, 2 \%$, etc. Intuitively if an area is growing at $3 \%$ this year, a drop to $1 \%$ growth can indicate the onset of economic turmoil. 
Table 5: $\beta_{1}$ estimates for alternative definitions of crisis, equation 20

\begin{tabular}{cccccc}
\hline $\begin{array}{c}\text { Drop in } \\
\text { propietors' } \\
\begin{array}{c}\text { income defining a } \\
\text { crisis (\%) }\end{array}\end{array}$ & $\begin{array}{c}\text { Average } \\
\text { duration of } \\
\text { expansions }\end{array}$ & $\begin{array}{c}\text { Number of } \\
\text { crises }\end{array}$ & $\begin{array}{c}\text { Coefficient on } \\
\text { duration in } \\
\text { equation 19 }\end{array}$ & $\begin{array}{c}\text { Standard } \\
\text { Error }\end{array}$ & T-statistics \\
\hline 0 & 3.30 & 1268 & -0.080 & 0.0212 & -3.767 \\
0.1 & 3.30 & 1259 & -0.078 & 0.0212 & -3.685 \\
0.2 & 3.29 & 1248 & -0.083 & 0.0211 & -3.928 \\
0.3 & 3.26 & 1231 & -0.079 & 0.0212 & -3.750 \\
0.4 & 3.26 & 1211 & -0.087 & 0.0213 & -4.069 \\
0.5 & 3.25 & 1199 & -0.084 & 0.0215 & -3.929 \\
0.6 & 3.23 & 1190 & -0.086 & 0.0221 & -3.863 \\
0.7 & 3.22 & 1177 & -0.082 & 0.0226 & -3.643 \\
0.8 & 3.21 & 1165 & -0.082 & 0.0228 & -3.601 \\
0.9 & 3.21 & 1155 & -0.083 & 0.0224 & -3.702 \\
1 & 3.21 & 1144 & -0.079 & 0.0223 & -3.547 \\
1.1 & 3.20 & 1135 & -0.077 & 0.0223 & -3.460 \\
1.2 & 3.19 & 1125 & -0.081 & 0.0223 & -3.625 \\
1.3 & 3.19 & 1119 & -0.082 & 0.0225 & -3.638 \\
1.4 & 3.17 & 1101 & -0.085 & 0.0229 & -3.703 \\
1.5 & 3.13 & 1089 & -0.090 & 0.0240 & -3.731 \\
1.6 & 3.13 & 1081 & -0.090 & 0.0241 & -3.726 \\
1.7 & 3.12 & 1067 & -0.092 & 0.0242 & -3.778 \\
1.8 & 3.12 & 1057 & -0.090 & 0.0246 & -3.676 \\
1.9 & 3.11 & 1050 & -0.089 & 0.0247 & -3.624 \\
2 & 3.05 & 1040 & -0.089 & 0.0259 & -3.421 \\
\hline
\end{tabular}

Note: Expansion as long as propietors' income growth $>0$

In Tables 6 and 7 we report estimates of $\beta_{1}$ in equation (19) and (20), respectively, for several different definitions of a crisis onset defined by different percentage levels of drops in income growth defining, 1 through $10 \%$, with the requirement that growth be positive in the year preceding the crisis. As before, we document the number of crises resulting from the various definitions, average expansion duration, and standard errors and t-statistics for the coefficient estimates.

Again, the resulting relationship between the duration of the expansion and the job growth at crisis onset is negative and significant for all the various definitions, showing the robustness of our empirical findings. 
Table 6: $\beta_{1}$ estimates for alternative definitions of crisis, equation 19

\begin{tabular}{cccccc}
\hline $\begin{array}{c}\text { Drop in growth } \\
\text { rate of propietors' } \\
\text { income defining a } \\
\text { crisis (\%) }\end{array}$ & $\begin{array}{c}\text { Average } \\
\text { duration of } \\
\text { expansions }\end{array}$ & $\begin{array}{c}\text { Number of } \\
\text { crises }\end{array}$ & $\begin{array}{c}\text { Coefficient on } \\
\text { duration in } \\
\text { equation 20 }\end{array}$ & $\begin{array}{c}\text { Standard } \\
\text { Error }\end{array}$ & T-statistics \\
\hline 1 & 3.47 & 2815 & -0.021 & 0.0106 & -2.005 \\
2 & 3.42 & 2667 & -0.026 & 0.0107 & -2.406 \\
3 & 3.39 & 2533 & -0.032 & 0.0093 & -3.447 \\
4 & 3.33 & 2375 & -0.034 & 0.0094 & -3.603 \\
5 & 3.26 & 2213 & -0.041 & 0.0102 & -4.056 \\
6 & 3.24 & 2076 & -0.041 & 0.0108 & -3.769 \\
7 & 3.20 & 1946 & -0.034 & 0.0105 & -3.292 \\
8 & 3.13 & 1806 & -0.038 & 0.0115 & -3.292 \\
9 & 3.10 & 1687 & -0.036 & 0.0128 & -2.773 \\
10 & 2.97 & 1556 & -0.028 & 0.0151 & -1.825 \\
\hline
\end{tabular}

Note: Expansion as long as propietors' income growth $>0$

Table 7: $\beta_{1}$ estimates for alternative definitions of crisis, equation 20

\begin{tabular}{cccccc}
\hline $\begin{array}{c}\text { Drop in growth } \\
\text { rate of propietors' } \\
\text { income defining a } \\
\text { crisis (\%) }\end{array}$ & $\begin{array}{c}\text { Average } \\
\text { duration of } \\
\text { expansions }\end{array}$ & $\begin{array}{c}\text { Number of } \\
\text { crises }\end{array}$ & $\begin{array}{c}\text { Coefficient on } \\
\text { duration in } \\
\text { equation 19 }\end{array}$ & $\begin{array}{c}\text { Standard } \\
\text { Error }\end{array}$ & T-statistics \\
\hline 1 & 3.47 & 2815 & -0.051 & 0.0145 & \\
2 & 3.42 & 2667 & -0.057 & 0.0148 & -3.531 \\
3 & 3.39 & 2533 & -0.063 & 0.0137 & -4.595 \\
4 & 3.33 & 2375 & -0.069 & 0.0141 & -4.911 \\
5 & 3.26 & 2213 & -0.071 & 0.0160 & -4.477 \\
6 & 3.24 & 2076 & -0.060 & 0.0160 & -3.741 \\
7 & 3.20 & 1946 & -0.052 & 0.0160 & -3.258 \\
8 & 3.13 & 1806 & -0.059 & 0.0168 & -3.480 \\
9 & 3.10 & 1687 & -0.057 & 0.0184 & -3.115 \\
10 & 2.97 & 1556 & -0.047 & 0.0199 & -2.367 \\
\hline
\end{tabular}

Note: Expansion as long as propietors' income growth $>0$ 